\title{
A spectral library for laser-induced fluorescence analysis as a tool for rare earth element identification
}

\author{
Margret C. Fuchs ${ }^{1}$, Jan Beyer ${ }^{2}$, Sandra Lorenz ${ }^{1}$, Suchinder Sharma ${ }^{1,2}$, Axel D. Renno ${ }^{1}$, \\ Johannes Heitmann ${ }^{2}$, and Richard Gloaguen ${ }^{1}$ \\ ${ }^{1}$ Helmholtz-Zentrum Dresden-Rossendorf, Helmholtz Institute Freiberg for Resource Technology, \\ Chemnitzer Str. 40, 09599 Freiberg, Germany \\ ${ }^{2}$ Institute of Applied Physics, TU Bergakademie Freiberg, Leipziger Strasse 23, 09599 Freiberg, Germany \\ Correspondence: Margret C. Fuchs (m.fuchs@hzdr.de)
}

Received: 1 October 2020 - Discussion started: 26 October 2020

Revised: 23 June 2021 - Accepted: 18 July 2021 - Published: 14 September 2021

\begin{abstract}
With the recurring interest in rare earth elements (REEs), laser-induced fluorescence (LiF) may provide a powerful tool for their rapid and accurate identification at different stages along their value chain. Applications to natural materials such as minerals and rocks could complement the spectroscopy-based toolkit for innovative, non-invasive exploration technologies. However, the diagnostic assignment of detected emission lines to individual REEs remains challenging because of the complex composition of natural rocks in which they can be found. The resulting mixed spectra and the large amount of data generated demand automated approaches of data evaluation, especially in mapping applications such as drill core scanning. $\mathrm{LiF}$ reference data provide the solution for robust REE identification, yet they usually remain in the form of tables of published emission lines. We show that a complete reference spectra library could open manifold options for innovative automated analysis.

We present a library of high-resolution LiF reference spectra using the Smithsonian rare earth phosphate standards for electron microprobe analysis. We employ three standard laser wavelengths $(325,442,532 \mathrm{~nm})$ to record representative spectra in the UV-visible to near-infrared spectral range $(340-1080 \mathrm{~nm})$. Excitation at all three laser wavelengths yielded characteristic spectra with distinct REE-related emission lines for $\mathrm{EuPO}_{4}, \mathrm{TbPO}_{4}$, $\mathrm{DyPO}_{4}$ and $\mathrm{YbPO}_{4}$. In the other samples, the high-energy excitation at $325 \mathrm{~nm}$ caused unspecific, broad-band defect emissions. Here, lower-energy laser excitation is shown to be successful for suppressing non-REE-related emission. At $442 \mathrm{~nm}$ excitation, REE reference spectra depict the diagnostic emission lines of $\mathrm{PrPO}_{4}, \mathrm{SmPO}_{4}$ and $\mathrm{ErPO}_{4}$. For $\mathrm{NdPO}_{4}$ and $\mathrm{HoPO}_{4}$ the most efficient excitation was achieved with $532 \mathrm{~nm}$. Our results emphasise the possibility of selective REE excitation by changing the excitation wavelength according to the suitable conditions for individual REEs. Our reference spectra provide a database for the transparent and reproducible evaluation of REE-bearing rocks. The LiF spectral library is available at zenodo.org and the registered DOI https://doi.org/10.5281/zenodo.4054606 (Fuchs et al., 2020). Primarily addressing the raw material exploration sector, it aids particularly the development of advanced data processing routines for $\mathrm{LiF}$ analysis but can also support further research on the REE luminescence in natural rocks or artificial compounds. It gives access to traceable data for the comparison of emission line positions, emission line intensity ratios and splitting into emission line sub-levels or can be used as reference or training data for automated approaches of component assignment.
\end{abstract}




\section{Introduction}

The exploding demand for rare earth elements (REEs) for the high-tech industry, e-mobility and the energy transition justifies the need for efficient detection methods all along the value chain, especially in raw material exploration and recycling but also in science and processing or production monitoring (e.g. National Research Council, 2008; Lima and Filho, 2015; Barakos et al., 2016; European Commission, 2014, 2018). Spectroscopy-based methods are of paramount importance in overcoming time- and cost-intensive exploration routines in a world of depleting, increasingly complex and more remote raw material deposits.

Reflectance spectroscopy has shown an immense potential for fast, non-invasive mineral mapping. Several studies particularly demonstrated advances in reflectance hyperspectral imaging (in the following abbreviated as HSI) of REEs in natural materials from close-range scanning of drill cores and outcrops or from drone-borne data of larger-scale areas (e.g. Boesche et al., 2015; Turner, 2015; Neave et al., 2016; Zimmermann et al., 2016; Booysen et al., 2019). However, an absorption feature-based identification relies in most application cases on single REEs (e.g. Nd, Pr, Sm), which then serve as pathfinders for the other REEs based on strong geochemical similarities and consequently assumptions of generic relationships during geological processes. Key to result validation are reference spectra. Established spectral libraries such as from the USGS (Kokaly et al., 2017) give access to the necessary reference data for automated identification routines. This trend is also recognised by Fasnacht et al. (2019), who released a new library explicitly dedicated to serve for advanced automated data processing including machine learning approaches.

Laser-induced fluorescence $(\mathrm{LiF})$ provides a particularly well-suited alternative for REE identification. The distinct, narrow emission lines in LiF spectra correspond to elementspecific electron excitation-radiative relaxation processes. The resulting energy release in the form of photons shows characteristic wavelengths dependent on the electronic configuration of the elements (i.e. the trivalent REE with a partially filled 4f-shell) and on the configuration of the element in relation to its neighbour within the crystal lattice (Gaft et al., 2005; Gaft and Panczer, 2013). The diagnostic LiF signatures deliver the spectral fingerprints that can be used in numerous applications in raw material characterisation.

Kauppinen et al. (2014) demonstrated the application of $\mathrm{LiF}$ for fast mineral mapping of, for example, drill cores, while others investigated the $\mathrm{LiF}$ for horizon control of mining machines (e.g. Nienhaus and Bayer, 2003) or quality control of mineral processing and sorting (e.g. Broicher, 2000, 2005). However, the mapping application cases focused on general measures of emission intensities or their ratios rather than on specific features in $\mathrm{LiF}$ spectra. Other studies emphasise the high potential of LiF for REE detection in natural rocks (Reisfeld et al., 1996; Gaft et al., 2005;
Lorenz et al., 2019; Seidel et al., 2019). Despite the promising studies, the method is not yet deployed in the raw material sector. To facilitate applications of $\mathrm{LiF}$ for REE detection in mineral exploration and related fields of material characterisation, the access to robust, traceable spectral reference data is needed.

$\mathrm{LiF}$ reference data are often very specific and limited (e.g. restricted to only a few REEs), and spectra are usually available only as plots (e.g. Czaja et al., 2008; Friis et al., 2010). Comprehensive summaries are given in the form of tables with emission band positions along with information on excitation conditions (e.g. Gaft et al., 2005) and, similarly, in some online databases (e.g. CSIRO, 2019; Barmarin, 2020). Such data limit emerging automated data analysis approaches to a few parameters, while other information stored in $\mathrm{LiF}$ spectra remains unspecified (e.g. relative intensities, emission sub-levels). Although not within scope of the presented study, such information opens manifold possibilities also for future research questions not only in the mineral exploration field. Nevertheless, the availability of new, sophisticated, automated data processing routines emphasise already today the need for digital reference data of complete spectra, comparable to those for HSI (e.g. Kokaly et al., 2017) or Raman spectroscopy (e.g. Lafuente et al., 2015). Such reference data are crucial to further develop and automate the LiF-based REE detection and analytical capacities for analyses of REE abundances and their spectral representation in natural rocks.

In this study, we present an open, digital LiF spectral library from REE phosphates as a traceable reference data repository that is available at https://zenodo.org, last access: 20 July 2021, DOI: https://doi.org/10.5281/zenodo.4054606 (Fuchs et al., 2020). The library comprises the spectral information as high-resolution data in the visible to near-infrared range $(350-1080 \mathrm{~nm})$ to cover the major REE diagnostic emissions. LiF spectral fingerprints of REEs in phosphates are important because phosphates represent a group of typical REE-bearing minerals, e.g. monazite-(Ce), monazite$(\mathrm{La})$, monazite-(Nd) and monazite-(Sm) $\left(\operatorname{LREE}\left(\mathrm{PO}_{4}\right)\right)$, xenotime- $(\mathrm{Y})$ and xenotime- $(\mathrm{Yb})\left(\mathrm{Y}\left(\mathrm{PO}_{4}\right)\right.$ and $\mathrm{Yb}\left(\mathrm{PO}_{4}\right)$, respectively), or apatites $\left(\mathrm{Ca}_{5}\left(\mathrm{PO}_{4}\right)_{3}(\mathrm{OH}, \mathrm{F}, \mathrm{Cl})\right)$. Those minerals are relevant in many REE deposits such as in Siilinjärvi and Korsnäs (Finland) (e.g. Goodenough et al., 2016), in Lovozero and Khibina (Kola Peninsula, Russia) (e.g. Kalashnikov et al., 2016) , in Bayan Obo (China) and Mt. Weld (Western Australia) (e.g. Emsbo et al., 2015; Lima and Filho, 2015), or in Ilimaussaq (South Greenland) (e.g. Zirner et al., 2015). We use reference material for electron microprobe analyses from the Smithsonian's Department of Mineral Sciences to base spectral results on well-studied and referenced material (Jarosewich and Boatner, 1991; Donovan et al., 2002).

Our study aims to provide a useful database for mineral characterisation in LiF-based REE exploration, in which particular target groups are developers of advanced data pro- 
cessing routines and of technical implementations but also various scientists working on further aspects of REE luminescence. Therefore, the scope of our study focuses on (1) characterising the observed emissions in $\mathrm{LiF}$ spectra of the Smithsonian REE phosphate standards by LiF, (2) investigating the suitability of three standard laser wavelengths $(325,442,532 \mathrm{~nm})$ with respect to excitation efficiency and selectivity, (3) introducing a LiF spectral library from REE phosphates as a transparent reference for robust evaluation of $\mathrm{LiF}$ data acquired from natural rocks, and (4) encouraging others to publish spectral data (a) to complement the REE spectral library and (b) to expand the published knowledge on variations related to the chemical and mineralogical composition of natural (host) materials.

\section{Material and methods}

\subsection{Rare earth element standards}

We used two sets of homogeneous, well-characterised, synthetic REE orthophosphates (crystal size of 0.5$3.0 \mathrm{~mm}$ ) from the Smithsonian National Museum of Natural History, Department of Mineral Sciences (sample IDs: NMNH 16484-NMNH 168499; Jarosewich and Boatner, 1991; Donovan et al., 2002, 2003; see Table 1; for available data sheets see Smithsonian National Museum of Natural History, 2019), to determine representative REE fluorescence spectra. The relatively simple crystallographic structure of the orthophosphates responsible for a simple defect configuration and the relatively pure chemical composition promote the material to deliver REE reference spectra without perturbances from mixed REEs or complex mineral hosts of natural materials.

Previous analyses of the REE orthophosphates confirmed a high quality of the material regarding REE purity (Jarosewich and Boatner, 1991; Donovan et al., 2002, 2003). However, Donovan et al. (2002) detected REE crosscontamination of mass fractions on the order of $10^{-4}$ by instrumental neutron activation analysis (NAA) and found $\mathrm{Pb}$ contamination in at least 7 out of the 16 samples (see Table 1). Based on their analytical data, Donovan et al. (2002) determined a roughly $2 \%-4 \%$ relative deviation from the expected (theoretical) sample composition but found only the $\mathrm{Pb}$ concentration in $\mathrm{CePO}_{4}, \mathrm{LaPO}_{4}$ and $\mathrm{SmPO}_{4}$ to possibly affect electron microprobe results. However, our recorded luminescence spectra do not indicate any $\mathrm{Pb}$-related emission features.

Both sets belong to the same original population of REE reference samples for electron microprobe analysis (Jarosewich and Boatner, 1991) and differ only by one being embedded in a disc of epoxy resin and one being available in the form of single grains (see Fig. 1). Together, the measured REEs in the given orthophosphate samples comprise $\mathrm{Sc}, \mathrm{Y}, \mathrm{Pr}, \mathrm{Nd}, \mathrm{Sm}, \mathrm{Eu}, \mathrm{Tb}, \mathrm{Dy}, \mathrm{Ho}, \mathrm{Er}, \mathrm{Tm}$ and Yb for embedded standards. From the same material production series, we
Table 1. Overview of rare earth element (REE) phosphate samples from the Smithsonian National Museum of Natural History used in this study for the LiF spectral library (based on Jarosewich and Boatner, 1991; Donovan et al., 2002, 2003; LREE: light REE; HREE: heavy REE; ID: identification number of the Smithsonian National Museum of Natural History; data sheets at Smithsonian National Museum of Natural History (2019)) Pb trace analysis values represent the average mass fraction of 10 measurements from instrumental neutron activation analysis. Values are given in wt $\% \times 10^{-2}$ to reduce number of zero digits. The given uncertainty values state 1 standard deviation.

\begin{tabular}{llccc}
\hline Sample & ID & $\begin{array}{c}\mathrm{REE}^{3+} \\
(\mathrm{wt} \%)\end{array}$ & $\begin{array}{c}\mathrm{PO}_{4}^{3-} \\
(\mathrm{wt} \%)\end{array}$ & $\begin{array}{c}\mathrm{Pb} \\
\left(\mathrm{wt} \% \times 10^{-2}\right)\end{array}$ \\
\hline LREE & & & & \\
\hline $\mathrm{ScPO}_{4}$ & NMNH 168495 & 32.12 & 67.88 & $0.00 \pm 0.00$ \\
$\mathrm{YPO}_{4}$ & NMNH 168499 & 48.35 & 51.65 & $0.00 \pm 0.00$ \\
$\mathrm{LaPO}_{4}$ & NMNH 168490 & 59.39 & 40.61 & $0.90 \pm 0.32$ \\
$\mathrm{CePO}_{4}$ & NMNH 168484 & 59.60 & 40.40 & $1.90 \pm 0.07$ \\
$\mathrm{PrPO}_{4}$ & NMNH 168493 & 59.73 & 40.27 & $0.92 \pm 0.04$ \\
$\mathrm{NdPO}_{4}$ & NMNH 168492 & 60.30 & 39.70 & $0.86 \pm 0.17$ \\
$\mathrm{SmPO}_{4}$ & NMNH 168494 & 61.28 & 38.72 & $0.86 \pm 0.13$ \\
EuPO $_{4}$ & NMNH 168487 & 61.54 & 38.46 & $0.64 \pm 0.16$ \\
$\mathrm{GdPO}_{4}$ & NMNH 168488 & 62.34 & 37.66 & $0.39 \pm 0.16$ \\
\hline $\mathrm{HREE}^{2}$ & & & & \\
\hline $\mathrm{TbPO}_{4}$ & NMNH 168496 & 62.59 & 37.41 & $0.00 \pm 0.00$ \\
$\mathrm{DyPO}_{4}$ & NMNH 168485 & 63.11 & 36.89 & $0.00 \pm 0.00$ \\
$\mathrm{HoPO}_{4}$ & NMNH 168489 & 63.45 & 36.55 & $0.00 \pm 0.00$ \\
ErPO $_{4}$ & NMNH 168486 & 63.78 & 36.22 & $0.00 \pm 0.00$ \\
$\mathrm{TmPO}_{4}$ & NMNH 168497 & 64.01 & 35.99 & $0.00 \pm 0.00$ \\
$\mathrm{YbPO}_{4}$ & NMNH 168498 & 64.56 & 35.44 & $0.00 \pm 0.00$ \\
LuPO $_{4}$ & NMNH 168491 & 64.81 & 35.19 & $0.00 \pm 0.00$ \\
\hline
\end{tabular}

additionally measured single grain specimens of the already mentioned REEs plus Ce, La and Lu. No diagnostic emission lines are expected for $\mathrm{Sc}, \mathrm{Y}, \mathrm{La}$ and $\mathrm{Lu}$ according to their electronic configuration, and hence, those four REE were not included in our library. The diagnostic emission lines of Gd lie outside the detection range.

\subsection{Measurement setup}

The measurement setup is shown in Fig. 2. The configuration represents a typical luminescence measurement setup in backscattering mode, in which the light paths of excitation to the sample and emitted luminescence from the sample are parallel. We used different laser wavelengths for $\mathrm{LiF}$ signal excitation: $325 \mathrm{~nm}$ (UV, He-Cd laser, focus spot $185 \mu \mathrm{m}, 14.58 \mathrm{~W} / \mathrm{cm}^{2}$ ), $442 \mathrm{~nm}$ (blue, He-Cd laser, focus spot $170 \mu \mathrm{m}, 16.73 \mathrm{~W} / \mathrm{cm}^{2}$ ) and $532 \mathrm{~nm}$ (green, diodepumped frequency-doubled Nd:YAG, focus spot $143 \mu \mathrm{m}$, $26.93 \mathrm{~W} / \mathrm{cm}^{2}$ ). The focus spot sizes and power densities (given in the previous sentence in brackets) are given as $1 / e^{2}$ of a Gaussian fit to the lateral intensity profile. 

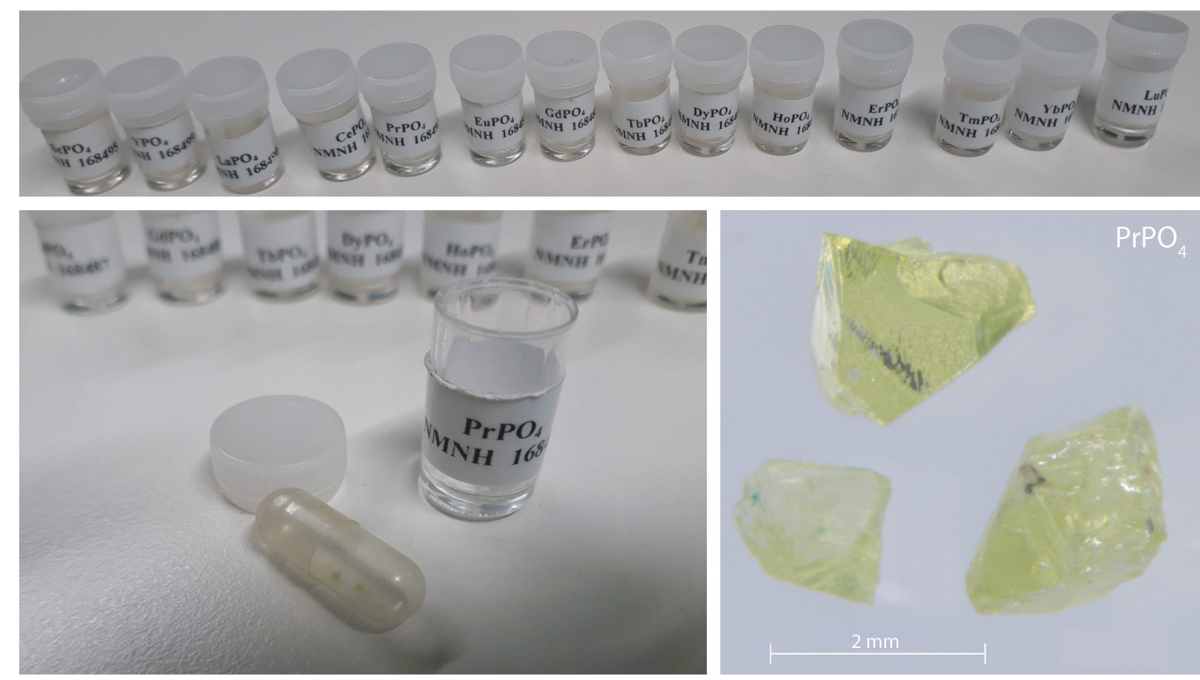

Figure 1. The reference REE orthophosphates from the National Museum of Natural History (example $\mathrm{PrPO}_{4}$ ).

The emitted luminescence was dispersed using a $50 \mathrm{~cm}$ monochromator unit Acton SP2560i with a $300 \mathrm{~g} / \mathrm{mm}$ grating and recorded with a charge-coupled device (CCD) camera (Princeton Instruments SPEC-10:100BR_eXcelon; 1340 channels, liquid nitrogen cooled). The used spectral detection range covers 340 to $1080 \mathrm{~nm}$. Appropriate long-pass filters (edges at 334, 450 and $550 \mathrm{~nm}$ ) ensured reliable separation of laser stimulation light from emitted luminescence and were furthermore applied to suppress second order diffraction signals in the long-wavelength part of the spectra. We measured all REE standards under continuous-wave excitation at room temperature and chose integration times between $300 \mathrm{~ms}$ and $10 \mathrm{~s}$ to optimise absolute signal intensities without saturating the CCD camera.

\subsection{Data processing}

The raw spectra were corrected for the spectral sensitivity of the detection unit with in-house calibration data for the respective technical setup. Consecutive data processing and visualisation were done using the $\mathrm{R}$ environment ( $\mathrm{R}$ Core Team, 2014). Spectra over the full detection range of 340$1080 \mathrm{~nm}$ required two separate measurements (long-pass filter of e.g. 334 and $550 \mathrm{~nm}$ ) to suppress the second order signals at double wavelength. For merging both, a merge segment was defined with the starting point set to $560 \mathrm{~nm}$ and the upper end defined according to the minimum intensity difference between both spectra. Within the merge segment, the final spectrum transitions smoothly from the first (measured with $334 \mathrm{~nm}$ long-pass filter covering the short wavelength range) to the second partial spectrum (measured with $550 \mathrm{~nm}$ long-pass filter covering the long wavelength range). Mathematically this means that the difference of the partial spectra multiplied by a linearly varying weighting factor from zero to one across the merge segment is added to the first spectrum.
Finally, the partial spectra were joined using the first spectrum at wavelengths shorter than $560 \mathrm{~nm}$, the calculated new merge segment of the overlapping range and the upper spectrum of the longer wavelengths above the calculated merge segment.

Spectra obtained from the set of embedded phosphate standards showed an intense broad-band emission attributed to the epoxy resin, in particular because of partly small and translucent sample crystals that are not perfectly exposed at the resin surface. We measured the epoxy resin at three locations next to REE crystals. The epoxy resin spectra show reproducible luminescence indicating material homogeneity and, accordingly, allow for subtraction from the REE sample spectra. Minor variations can be attributed to signal noise, which was removed by calculating a mean spectrum from the three epoxy resin spectra. We then subtracted the epoxyresin-related emission from the REE sample spectra. This operation is comparable to the removal of a non-sample-related background continuum, allowing for an unbiased detection of remaining REE-related emission lines, as well as of absorption features.

Peak detection was made challenging by clustered emission lines and by distinguishing small REE emission peaks from noise artefacts. Therefore, merged spectra were smoothed in a running mean interval of $1.2 \mathrm{~nm}$ to reduce the noise while keeping the spectral sampling interval. The smoothing interval was carefully chosen to retain emissions of low intensity and details of clustered narrow emission lines. In the case of emission bands with clusters of many narrow emission lines, an automated peak detection was complicated and resulted typically only in the detection of the most prominent peak. To identify also the individual emission lines within emission bands, we calculated a background continuum based on the spline-smoothed running minimum (degrees of freedom 50, bin size $1.2 \mathrm{~nm}$ ). After re- 


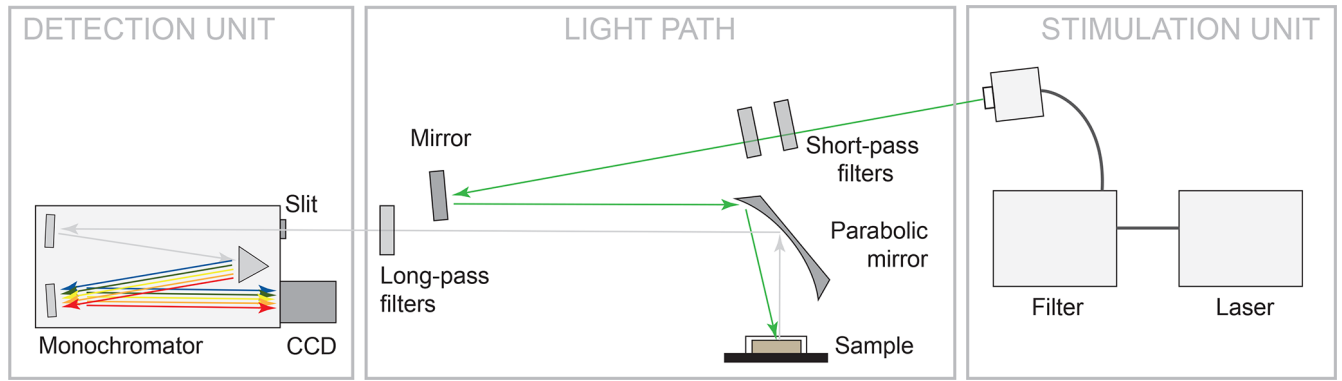

Figure 2. Scheme of technical setup for the laser-induced fluorescence (LiF) measurements.

moving this background continuum, we detected all peaks above a threshold of typically 2 standard deviations of the entire spectrum.

\subsection{Sample homogeneity}

Recorded LiF spectra represent a single measurement spot where the signal to noise ratio was best. We checked for spatial variations and representativity of the selected LiF measurement spot using hyperspectral reflectance imaging. The images from an FX10 camera (Spectral Imaging Ltd.) with a spatial resolution of $0.17 \mathrm{~mm}$ depict the sample grains with 5 to 25 pixels (pure sample pixels), each containing the reflectance spectrum in a range of $400-1000 \mathrm{~nm}$. All spectra of the measured REE sample grain were analysed for features deviating from expected REE absorptions. The reflectance data were analysed using the $\mathrm{R}$ package "hyperSpec" (Beleites and Sergo, 2018) and compared to the reflectance spectral library of the USGS (Kokaly et al., 2017).

The obtained reflectance spectra of pure sample pixels were consistent with respect to absorption feature position (Fig. 3). Variations in signal intensities have minor influences on relative absorption depth (standard deviation below $5 \%$ ). The reference spectral library for standard material from the USGS (Kokaly et al., 2017) comprises only REE oxides and in some cases chlorides, but no phosphates, but a comparison of absorption positions confirmed agreement with observed absorption features in our REE samples. None of the pure sample spectra contained additional absorption features, and thus, reflectance spectra attest to the spatial homogeneity and good sample quality.

\section{Results}

\subsection{REE reference spectra at $325 \mathrm{~nm}$ laser excitation}

With a laser excitation at $325 \mathrm{~nm}$ the Smithsonian REE phosphate samples yielded representative spectra for $\mathrm{Ce}^{3+}, \mathrm{Nd}^{3+}$, $\mathrm{Eu}^{3+}, \mathrm{Tb}^{3+}$ and $\mathrm{Dy}^{3+}$ (Fig. 4). Prominent emission lines with high signal to noise ratios allow for an unequivocal assignment of transitions and represent the diagnostic features needed for a LiF-based REE identification. The high spectral resolution (spectral sampling $0.13 \mathrm{~nm}$ ) of the measurement setup enables us to separate multiple lines within emission clusters associated with the splitting of transitions into sublevels (Stark level splitting) as observed particularly in the spectra of $\mathrm{Nd}^{3+}, \mathrm{Tb}^{3+}$ and $\mathrm{Dy}^{3+}$ (Fig. 4). Table 2, therefore, differentiates between the most intense emission lines (main) and additionally detected less intense emission lines of the same emission band (minor).

For $\mathrm{CePO}_{4}$, the excitation results in a broad-band emission with a maximum at $420 \mathrm{~nm}$ (Fig. 4). The very broad emission is difficult to interpret based on our results and goes beyond the scope of this study. In general, it overlaps with the characteristic $\mathrm{Ce}^{3+}$ emission band around $360 \mathrm{~nm}$ that is associated with a 5d-4f transition (e.g. Reisfeld et al., 1996; Gaft et al., 2005; Shalapska et al., 2014). Several studies report broadened Ce-related peaks and discuss reasons behind them; for example, Shalapska et al. (2014) identified a peak doublet with the peak distance dependent on the site symmetry in the crystal lattice, and Chen et al. (2014) observed broadened emission in the range between 310 and $410 \mathrm{~nm}$ resulting from mixed phases of a monoclinic and hexagonal lattice. The Ce-related emission band appears less broad and shifts towards lower wavelengths in the two non-luminescent samples of $\mathrm{LuPO}_{4}$ and $\mathrm{YPO}_{4}$ (grey lines in Fig. 4, both samples from same set of Smithsonian REE phosphate standards; see Table 1). $\mathrm{LuPO}_{4}$ contains cerium at a mass fraction of $(0.1 \pm 0.2) \times 10^{-3}$ (NAA results according to Donovan et al., 2002) and reveals the maximum emission of $\mathrm{Ce}^{3+}$ at $362 \mathrm{~nm}$ (FWHM $356-373 \mathrm{~nm}$ ). $\mathrm{YPO}_{4}$ contains cerium at a mass fraction of $(0.5 \pm 0.6) \times 10^{-3}$ (NAA results according to Donovan et al., 2002), and here the maximum emission of $\mathrm{Ce}^{3+}$ lies at $359 \mathrm{~nm}$ (FWHM $352-365 \mathrm{~nm}$ ).

The $\mathrm{NdPO}_{4}$ spectrum depicts a prominent cluster of distinct emission lines peaking at $1059 \mathrm{~nm}$ and a secondary cluster of less intense emissions at $908 \mathrm{~nm}$ (Fig. 4). The two emission bands represent ${ }^{4} F_{3 / 2}-{ }^{4} I_{11 / 2}$ and ${ }^{4} F_{3 / 2}{ }^{4} I_{9 / 2}$ transitions, respectively (e.g. Reisfeld et al., 1996; Gaft et al., 2005; Czaja et al., 2012; Shalapska et al., 2014). Emission bands at shorter wavelengths ( $<850 \mathrm{~nm}$; Gaft et al., 2005) were not observed during measurements and hence are not recorded in our phosphate reference spectra. Nevertheless, the two observed $\mathrm{Nd}^{3+}$ emission bands are prominent and 


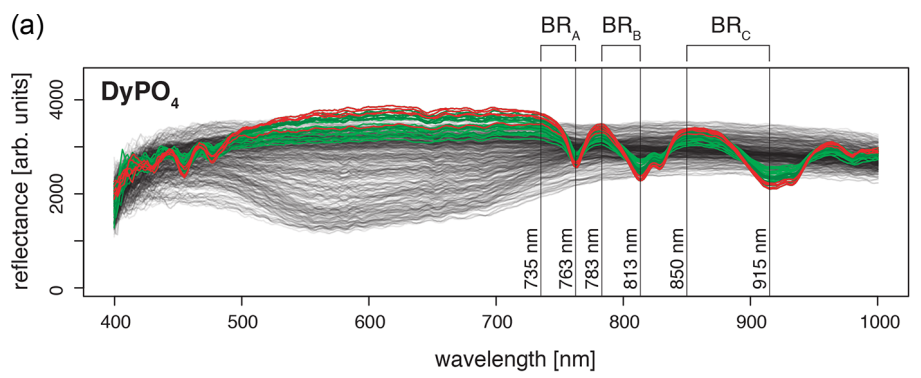

(b)

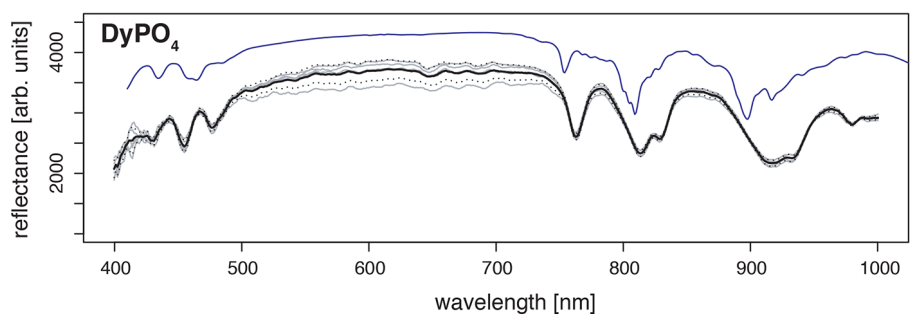

Extraction of reflectance sample spectra

$\left(B R_{\text {mean }}=\operatorname{mean}\left(B R_{A}, B R_{B}, B R_{C}\right)\right.$

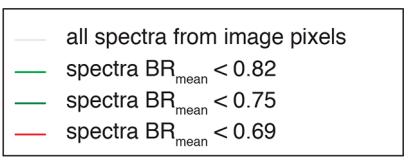

Reflectance sample spectrum (mean)

\begin{tabular}{ll|}
- & sample spectra $\left(\mathrm{BR}_{\text {mean }}<0.69\right)$ \\
- & mean spectrum \\
$\cdots . .$. & standard deviation \\
- & $\mathrm{Dy}_{2} \mathrm{O}_{3}$ reference (USGS) \\
\hline
\end{tabular}

Figure 3. Spatial homogeneity evaluation with hyperspectral reflectance images from a SPECIM FX10 camera with a spatial resolution of $0.17 \mathrm{~mm}$ (example DyPO 4 ). (a) For REE spectra extraction from all spectra of a measured scene (image), the mean of three band ratios was calculated to reduce influences from noise and ensure accurate identification of sample spectra (pixels containing spectra from the sample grain, in the text referred to as pure sample pixels). Bands were selected according to the position of diagnostic absorption features (BR $=$ band ratio representing the ratio of signal intensities at two given wavelengths). (b) A mean spectrum was calculated from all pure sample pixels. The standard deviation is given as an indication of the variability between spectra of pure sample pixels. The resulting REE absorption spectrum (mean spectrum) was compared to reference data from the USGS spectral library (Kokaly et al., 2017).

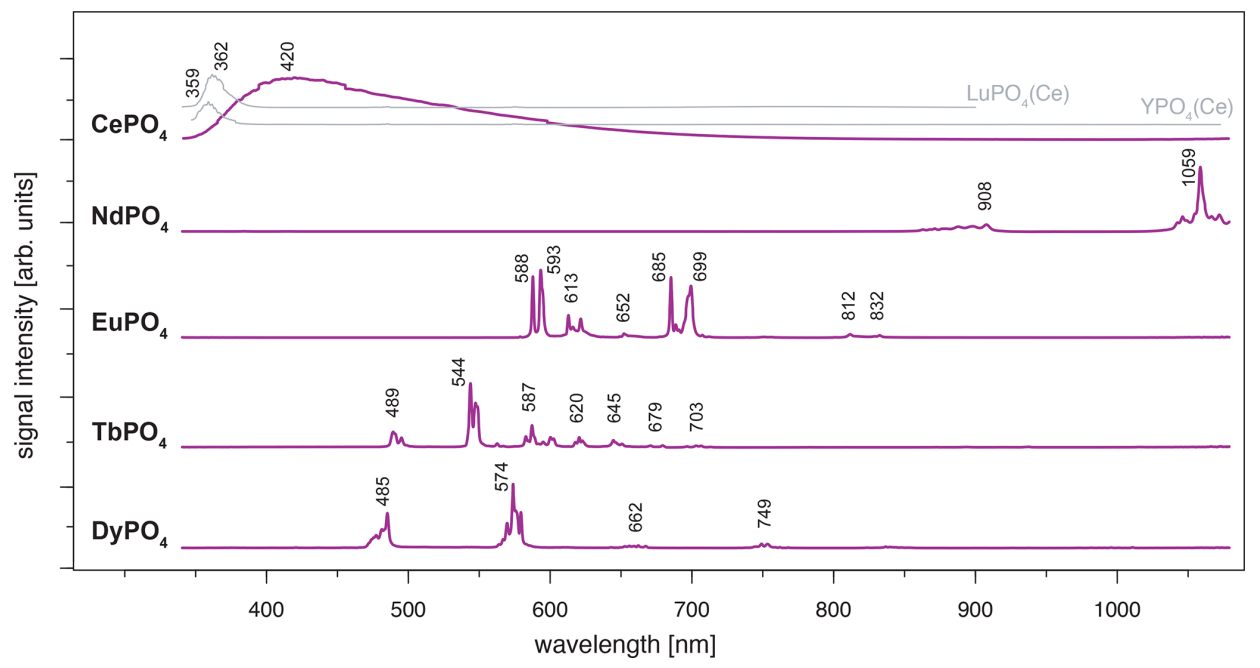

Figure 4. LiF reference spectra obtained with $325 \mathrm{~nm}$ laser excitation depict the diagnostic emission lines for the $\mathrm{REE}_{\mathrm{phosph}}$ ates $\mathrm{NdPO}_{4}$, $\mathrm{EuPO}_{4}, \mathrm{TbPO}_{4}$ and $\mathrm{DyPO}_{4}$ (given values represent wavelength of most intense emission in nanometres for each transition; cf. Table 2). $\mathrm{CePO}_{4}$ is included for completeness, and diagnostic emissions are shown by the grey lines representing spectra from two non-luminescent REE $\mathrm{PO}_{4}$ samples with cerium contaminations (see further explanation in the text along with cerium concentrations in those samples based on neutron activation analysis, NAA, results).

represent diagnostic features as they do not overlap with emissions of other REEs.

The spectrum of $\mathrm{EuPO}_{4}$ (Fig. 4) shows distinct emission lines at 588, 593,612, 651 and $699 \mathrm{~nm}$, representing five transitions from ${ }^{5} D_{0}$ to ${ }^{7} F_{i}(i=0,1,2,3,4$; Gaft et al.,
2005; Friis et al., 2010; Shalapska et al., 2014). The spectrum indicates splitting into sub-level emissions. Triplets of emission lines are recorded for the transitions to ${ }^{7} F_{2}$ and ${ }^{7} F_{4}$ with additional prominent lines at 622 and $685 \mathrm{~nm}$ and a line of minor intensity at 616 and $689 \mathrm{~nm}$, respectively. We observe 
two additional weak emission lines at 812 and $832 \mathrm{~nm}$. These rarely described emissions relate to the ${ }^{7} F_{6}$ transition (Binnemans, 2015). The emission pattern corresponds to $\mathrm{Eu}^{3+}$ observed in apatite (Reisfeld et al., 1996), in which the ratio of emission intensities for ${ }^{5} D_{0}$ to ${ }^{7} F_{2}$ and ${ }^{5} D_{0}$ to ${ }^{7} F_{1}$ is low. However, the detailed spectroscopic sample characterisation can be found in Sharma et al. (2019).

The emission lines in the $\mathrm{TbPO}_{4}$ spectrum represent five prominent transitions (from ${ }^{5} D_{4}$ to ${ }^{7} F_{i}, i=6,5,4,3,2$ ) and two weak transitions (from ${ }^{5} D_{4}$ to ${ }^{7} F_{1}$ and ${ }^{7} F_{0}$ ) (Nazarov et al., 2009; Shalapska et al., 2014; Fang et al., 2017). The transitions are evident as clusters of multiple emission lines with maximum intensities at 489, 544, 587, 587, 620, 645, 679 and $703 \mathrm{~nm}$ (Fig. 4). Reisfeld et al. (1996) and Gaft et al. (2005) reported emission lines below $440 \mathrm{~nm}$ for the phosphate minerals apatite and monazite. Those transitions from ${ }^{5} D_{3}$ to ${ }^{7} F_{i}(i=6,5,4)$ are not evident in our sample spectrum.

The $\mathrm{DyPO}_{4}$ spectrum displays narrow emission lines with two prominent bands at 485 and $574 \mathrm{~nm}$ and two weak emission bands at 662 and $749 \mathrm{~nm}$. The clustered emission lines correspond to the transitions ${ }^{4} F_{9 / 2}$ to ${ }^{6} H_{i}(i=$ 15/2,13/2,11/2,9/2; Reisfeld et al., 1996; Gaft et al., 2005; Friis et al., 2010). Our instrumental setup allows for a detection of separate sub-level emission lines corresponding to effects of the phosphate crystal field. Absorption spectroscopy suggests sufficient $\mathrm{Dy}^{3+}$ excitation when using a $325 \mathrm{~nm}$ laser, although higher efficiency can potentially be achieved using a slightly longer wavelength laser (e.g. 352 or $366 \mathrm{~nm}$; Friis et al., 2010).

\subsection{Absorption features in REE spectra at $325 \mathrm{~nm}$ laser excitation}

Spectra of several REE phosphates, especially $\mathrm{PrPO}_{4}$, $\mathrm{SmPO}_{4}, \mathrm{HoPO}_{4}, \mathrm{ErPO}_{4}$ and $\mathrm{TmPO}_{4}$, are dominated by a very broad emission band between 350 and $800 \mathrm{~nm}$ when using $325 \mathrm{~nm}$ laser excitation (Fig. 5), irrespective of the sample being embedded in epoxy resin (see Fig. 5 dark-violet spectra, $D=$ epoxy disc sample) or in the form of standalone single grains (see Fig. 5 violet spectra, $\mathrm{SG}=$ single grain sample). The broad emission band is intersected by prominent absorption features. A comparison with the USGS spectral library for reflectance data (Kokaly et al., 2017) and absorption positions reported in the literature (e.g. White, 1967; Boesche et al., 2015; Turner et al., 2014) confirms that absorptions match with respective REE-reference spectra.

The broad, unspecific emission band causes strong masking of most REE-diagnostic emission lines $<650 \mathrm{~nm}$. In the case of REEs with diagnostic emission lines $>650 \mathrm{~nm}$, the broad-band emission is less problematic because observed patterns in the long wavelength region may be sufficient for the REE identification (e.g. in the case of $\mathrm{ErPO}_{4}$, spectrum of the single grain (SG) specimen in Fig. 5). Such $325 \mathrm{~nm}$ excited spectra depict both absorptions and emissions in
Table 2. Overview of detected emission lines and corresponding transitions for the REE phosphates $\mathrm{NdPO}_{4}, \mathrm{EuPO}_{4}, \mathrm{TbPO}_{4}$, and $\mathrm{DyPO}_{4}$ that were successfully excited at $325 \mathrm{~nm}$ and cerium emission measured in $\mathrm{YPO}_{4}$ and $\mathrm{LuPO}_{4}\left(\lambda_{\text {exc }}\right.$ : excitation wavelength; $\lambda_{\text {emi }}$ : emission wavelength; main: most intense emission line; minor: additionally detected, less intense emission lines of the same emission band).

\begin{tabular}{|c|c|c|c|}
\hline \multicolumn{4}{|c|}{$\lambda_{\mathrm{exc}}: 325 \mathrm{~nm}$} \\
\hline Centre & $\begin{array}{r}\lambda_{\text {emi }}(\text { main }) \\
(\mathrm{nm})\end{array}$ & $\begin{array}{r}\lambda_{\text {emi }}(\text { minor }) \\
(\mathrm{nm})\end{array}$ & Transition \\
\hline $\mathrm{Ce}^{3+\mathrm{a}}$ & 359 & & $5 d-4 f$ \\
\hline $\mathrm{Ce}^{3+b}$ & 362 & & $5 d-4 f$ \\
\hline \multirow[t]{2}{*}{$\mathrm{Nd}^{3+}$} & 908 & $863,888,898$ & ${ }^{4} F_{3 / 2}{ }^{-4} I_{9 / 2}$ \\
\hline & 1059 & $1043,1046,1067,1072$ & ${ }^{4} F_{3 / 2}-{ }^{4} I_{11 / 2}$ \\
\hline \multirow[t]{6}{*}{$\mathrm{Eu}^{3+}$} & 588 & & ${ }^{5} D_{0}-{ }^{7} F_{0}$ \\
\hline & 593 & & ${ }^{5} D_{0}-{ }^{7} F_{1}$ \\
\hline & 613 & 616,622 & ${ }^{5} D_{0}-{ }^{7} F_{2}$ \\
\hline & 652 & & ${ }^{5} D_{0}-{ }^{7} F_{3}$ \\
\hline & 685 & 689,699 & ${ }^{5} D_{0}-{ }^{7} F_{4}$ \\
\hline & & 812,832 & ${ }^{5} D_{0}-{ }^{7} F_{6}$ \\
\hline \multirow[t]{7}{*}{$\mathrm{Tb}^{3+}$} & 489 & 495 & ${ }^{5} D_{4}-{ }^{7} F_{6}$ \\
\hline & 544 & 547,549 & ${ }^{5} D_{4}-{ }^{7} F_{5}$ \\
\hline & 587 & $582,595,600,602$ & ${ }^{5} D_{4}-{ }^{7} F_{4}$ \\
\hline & 620 & 618,622 & ${ }^{5} D_{4}-{ }^{7} F_{3}$ \\
\hline & 645 & 650 & ${ }^{5} D_{4}-{ }^{7} F_{2}$ \\
\hline & 679 & 671 & ${ }^{5} D_{4}-{ }^{7} F_{1}$ \\
\hline & 703 & 706 & ${ }^{5} D_{4}-{ }^{7} F_{0}$ \\
\hline \multirow[t]{4}{*}{$\mathrm{Dy}^{3+}$} & 485 & 477,481 & ${ }^{4} F_{9 / 2}-{ }^{6} H_{15 / 2}$ \\
\hline & 574 & 570,579 & ${ }^{4} F_{9 / 2}-{ }^{6} H_{13 / 2}$ \\
\hline & 662 & 656,667 & ${ }^{4} F_{9 / 2}-{ }^{6} H_{11 / 2}$ \\
\hline & 749 & 753 & ${ }^{4} F_{9 / 2}-{ }^{6} H_{9 / 2}$ \\
\hline
\end{tabular}

the same spectrum. The REE-related absorption features are recorded at wavelength $<800 \mathrm{~nm}$ and diagnostic emission lines in the spectral region $>650 \mathrm{~nm}$. To suppress the broadband emission and unravel the REE emission lines of interest, longer wavelength laser excitation proved successful.

\subsection{REE reference spectra at $442 \mathrm{~nm}$ laser excitation}

When using $442 \mathrm{~nm}$ laser excitation, the same diagnostic emission patterns were recorded for the above-presented REE $\mathrm{PO}_{4}$ samples $\left(\mathrm{NdPO}_{4}, \mathrm{EuPO}_{4}, \mathrm{TbPO}_{4}\right.$ and $\left.\mathrm{DyPO}{ }_{4}\right)$. Only the excitation efficiency appeared to be less as signal to noise ratios decreased, in particular for $\mathrm{NdPO}_{4}$ but also for $\mathrm{TbPO}_{4}$ and $\mathrm{DyPO}_{4}$. Additionally, representative LiF spectra could be acquired for $\mathrm{PrPO}_{4}, \mathrm{SmPO}_{4}$ and $\mathrm{ErPO}_{4}$.

Excitation with the $442 \mathrm{~nm}$ laser allows us to unravel distinct $\mathrm{Pr}^{3+}$-related emission lines in the $\mathrm{PrPO}_{4}$ reference spectrum at 498, 526, 617, 642 and $724 \mathrm{~nm}$ (see Fig. 6 and Table 3) corresponding to the dominant transitions described by Gaft et al. (2005) (first, third and fourth emission lines) and Zhou et al. (2012) (first four emission lines). Additionally, Liang et al. (2017), Prasad et al. (2018), and Runowski 


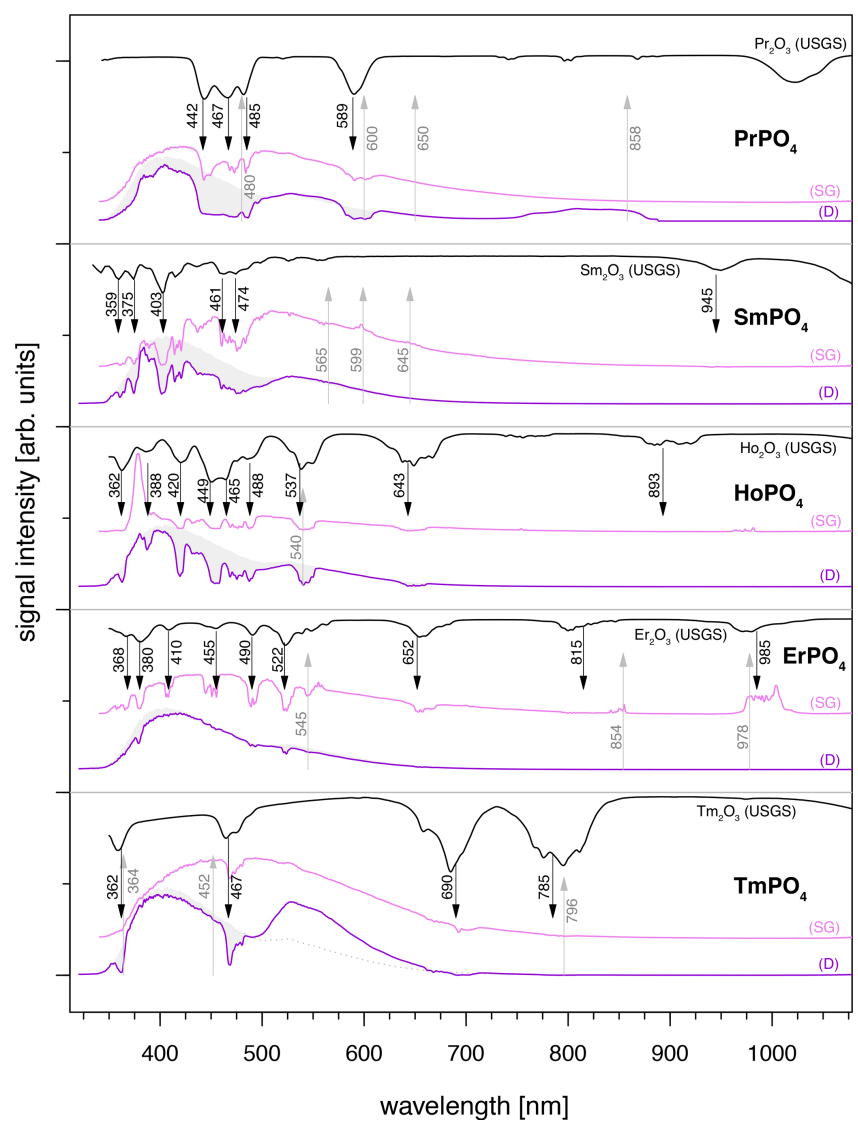

Figure 5. REE spectra illustrating diagnostic absorption features within prominent broad-band emissions at wavelengths $<800 \mathrm{~nm}$ and REE emission lines for those $>650 \mathrm{~nm}$. Violet and pink LiF spectra were measured using laser excitation at $325 \mathrm{~nm}$ for both sample specimens ( $D$ : samples embedded in disc; SG: single grain samples). Grey shaded area represents epoxy resin mean spectrum expected for $D$ samples without absorption features. Emissions $>650 \mathrm{~nm}$ are better visible in SG samples due to the lower intensity of the broad-band luminescence. Black reflectance spectra depict reference data from the USGS library (Kokaly et al., 2017).

et al. (2019) recorded also the emissions above $700 \mathrm{~nm}$. The transitions originate in ${ }^{3} P_{0}$ or ${ }^{3} P_{1}$ (Zhou et al., 2012; Prasad et al., 2018; Runowski et al., 2019), in which the comparison between reported and observed emission wavelengths indicates that both origins are possible and the (relative) dominance of one or the other decided the observed emission position (see Table 3). The transition's final states are ${ }^{3} H_{i}$ $(i=4,5,6)$ and ${ }^{3} F_{j}(j=2,4)$ (Zhou et al., 2012; Shalapska et al., 2014; Prasad et al., 2018; Runowski et al., 2019). Prasad et al. (2018) identified the ${ }^{1} D_{2}$ state to be the transition origin for the prominent Pr emission at around $600 \mathrm{~nm}$, as well as Gaft et al. (2005), who also attributed the emission around $500 \mathrm{~nm}$ to the same origin. However, the observed positions lie at slightly (around $10 \mathrm{~nm}$ ) higher emission wavelengths that agree better with positions found by, for example, Friis et al. (2010) and Runowski et al. (2019) and poten- tially result from a superposition of different transitions originating at certain portions from ${ }^{3} P_{0},{ }^{3} P_{1}$ and ${ }^{1} D_{2}$. Nevertheless, the origin of this rather large shift of $10 \mathrm{~nm}$ is currently unknown and will require in-depth investigation beyond the scope of this study.

The $442 \mathrm{~nm}$ laser-induced $\mathrm{SmPO}_{4}$ spectrum depicts prominent emission line clusters at 560, 597 and $643 \mathrm{~nm}$ and a cluster of minor intensity at $702 \mathrm{~nm}$ (Fig. 6). The first three emission lines correspond to $\mathrm{Sm}^{3+}$ transitions from ${ }^{4} G_{5 / 2}$ to ${ }^{6} H_{i}(i=5 / 2,7 / 2,9 / 2$; see Table 3$)$ in line with observations from Gaft et al. (2005), Friis et al. (2010), Czaja et al. (2012), Shalapska et al. (2014), and Guan et al. (2016). The pattern of four emission lines with the second line as most efficient emission resembles well observations by, for example, Ha et al. (2016), Wantana et al. (2017), and Yashodha et al. (2019), who assigned the fourth transition to ${ }^{6} H_{11 / 2}$. However, this transition has been attributed to a luminescence band observed at $720 \mathrm{~nm}$ by Friis et al. (2010). Influences from $\mathrm{Sm}^{2+}$ centres are considered to be unlikely because of measurements at room temperature and the absence of the $734 \mathrm{~nm}$ emission line (Gaft et al., 2005). Another explanation for the observed $700 \mathrm{~nm}$ emission cluster and potential source for peak broadening of the around $600 \mathrm{~nm}$ and $700 \mathrm{~nm}$ emission clusters could be the minimally detected Eu contamination in the $\mathrm{SmPO}_{4}$ sample (see NAA results in Donovan et al., 2002). The very weak near-infrared emission features around 900-950 $\mathrm{nm}$ may indicate additional, less often observed Sm emission features from ${ }^{4} G_{5 / 2}$ to ${ }^{6} F_{i}$ transitions $(i=1 / 2,3 / 2,5 / 2)$ (e.g. Ahmed and Iftikhar, 2019), in which, for example, Samanta et al. (2016) ascribe the latter transition around $950 \mathrm{~nm}$ to energy transfer from $\mathrm{Ce}$ (see small contaminations of $\mathrm{Ce}$ in NAA results in Donovan et al., 2002). A Nd contamination with corresponding emission lines in the same wavelength region (around $900 \mathrm{~nm}$ ) is not evident in NAA results (Donovan et al., 2002).

Laser excitation of $\mathrm{ErPO}_{4}$ at $442 \mathrm{~nm}$ unravels an emission at $550 \mathrm{~nm}$, besides the emission at $855 \mathrm{~nm}$ and the prominent cluster between 977 and 1004 nm (see Fig. 6), which were already detected at $325 \mathrm{~nm}$ excitation (see above). This first line represents an important diagnostic emission in the visible range (e.g. Reisfeld et al., 1996; Gaft et al., 1998; Friis et al., 2010). Gaft et al. (2005) assign respective emission lines to transitions from ${ }^{4} S_{3 / 2}$ to ${ }^{4} I_{i}(i=15 / 2,9 / 2)$ (first two lines) and ${ }^{4} I_{11 / 2}$ to ${ }^{4} I_{15 / 2}$ (third line) (see Table 3 ). Among others, Czaja et al. (2012) attribute another emission line at about $653 \mathrm{~nm}$ to $\mathrm{Er}^{3+}$ that is only weakly present in our reference $\mathrm{ErPO}_{4}$ spectrum (see Fig. 6) and identify the transition from ${ }^{4} F_{9 / 2}$ to ${ }^{4} I_{15 / 2}$ to be responsible for this emission.

\subsection{REE reference spectra at $532 \mathrm{~nm}$ laser excitation}

When using $532 \mathrm{~nm}$ laser excitation, the diagnostic emission lines already described above for $325 \mathrm{~nm}$ excitation (see Sect. 3.1) were recorded for the samples $\mathrm{NdPO}_{4}, \mathrm{EuPO}_{4}$, $\mathrm{TbPO}_{4}$ and $\mathrm{DyPO}_{4}$. Especially efficient was the $532 \mathrm{~nm}$ laser 


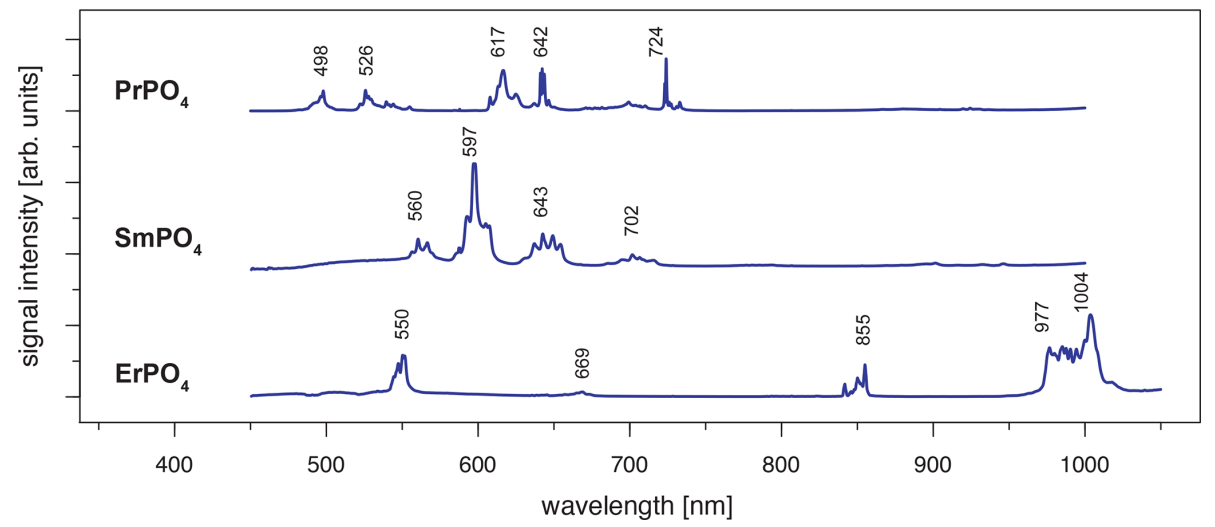

Figure 6. $\mathrm{LiF}$ reference spectra obtained with $442 \mathrm{~nm}$ laser excitation depict the diagnostic emission lines for the REE phosphates PrPO $\mathrm{SmPO}_{4}$ and $\mathrm{ErPO}_{4}$ (given values represent wavelength of most intense emission in nanometres for each transition; cf. Table 3).

Table 3. Overview of detected emission lines and corresponding transitions for those REEs that were successfully excited with the $442 \mathrm{~nm}$ laser (potential assignments to transitions are given in brackets).

\begin{tabular}{|c|c|c|c|}
\hline \multicolumn{4}{|c|}{$\lambda_{\text {exc }}: 442 \mathrm{~nm}$} \\
\hline Centre & $\begin{array}{r}\lambda_{\text {emi }}(\text { main }) \\
(\mathrm{nm})\end{array}$ & $\begin{array}{r}\lambda_{\text {emi }}(\text { minor }) \\
(\mathrm{nm})\end{array}$ & Transition \\
\hline \multirow[t]{5}{*}{$\operatorname{Pr}^{3+}$} & 498 & & ${ }^{3} \mathrm{P}_{0}-{ }^{3} H_{4}$ \\
\hline & 526 & $539,544,555$ & ${ }^{3} \mathrm{P}_{0}-{ }^{3} H_{5}$ \\
\hline & 617 & 608,625 & $\left({ }^{3} \mathrm{P}_{1},{ }^{3} \mathrm{P}_{0}\right)-{ }^{3} H_{6}$ \\
\hline & 642 & 637,647 & ${ }^{3} \mathrm{P}_{0}-{ }^{3} F_{2}$ \\
\hline & 724 & & ${ }^{3} \mathrm{P}_{0}-{ }^{3} F_{4}$ \\
\hline \multirow[t]{5}{*}{$\mathrm{Sm}^{3+}$} & 560 & 567 & ${ }^{4} \mathrm{G}_{5 / 2}-{ }^{6} H_{5 / 2}$ \\
\hline & 597 & 593,607 & ${ }^{4} \mathrm{G}_{5 / 2}-{ }^{6} H_{7 / 2}$ \\
\hline & 643 & $637,649,654$ & ${ }^{4} \mathrm{G}_{5 / 2}-{ }^{6} H_{9 / 2}$ \\
\hline & 702 & 716 & $\left({ }^{4} \mathrm{G}_{5 / 2}-{ }^{6} H_{11 / 2}\right)$ \\
\hline & $900-950$ & & ${ }^{4} G_{5 / 2}-{ }^{6} F_{(1 / 2,3 / 2,5 / 2)}$ \\
\hline$\left(\mathrm{Sm}^{2+}\right.$ & 702 & 716 & $\left.{ }^{7} D_{0}-{ }^{7} F_{1}\right)$ \\
\hline \multirow[t]{4}{*}{$\mathrm{Er}^{3+}$} & 550 & 547 & ${ }^{4} S_{3 / 2}-{ }^{4} I_{15 / 2}$ \\
\hline & 669 & & ${ }^{4} F_{9 / 2}-{ }^{4} I_{15 / 2}$ \\
\hline & 855 & 842,850 & ${ }^{4} \mathrm{~S}_{3 / 2}-{ }^{4} I_{9 / 2}$ \\
\hline & 1004 & $977,985,990,994$ & ${ }^{4} I_{11 / 2}-{ }^{4} I_{15 / 2}$ \\
\hline
\end{tabular}

excitation for $\mathrm{NdPO}_{4}$. Additional reference spectra including the main diagnostic emission lines were recorded for $\mathrm{HoPO}_{4}$ and $\mathrm{YbPO}_{4}$.

For $\mathrm{HoPO}_{4}$, the diagnostic emission line around $540 \mathrm{~nm}$ (e.g. Gaft et al., 2005; Qin et al., 2011; Pandey and Swart, 2016) was masked by broad-band luminescence with $\mathrm{Ho}^{3+}$. related absorptions (e.g. Turner et al., 2014; Kokaly et al., 2017) when using 325 and $442 \mathrm{~nm}$ laser excitation (see above). The $532 \mathrm{~nm}$ excited spectrum captures only emissions above $550 \mathrm{~nm}$ but successfully suppressed the masking broad-band luminescence below $700 \mathrm{~nm}$. Recorded emission lines cluster at 662, 754 and $982 \mathrm{~nm}$ (see Fig. 7 and Table 4). The first, relatively weak emission line corresponds to a ${ }^{5} F_{5}$ to ${ }^{5} I_{8}$ transition (e.g. Friis et al., 2010; Qin et al.,
2011; Pandey and Swart, 2016), while the second, more intense emission cluster results from a ${ }^{5} F_{4} /{ }^{5} \mathrm{~S}_{2}$ to ${ }^{5} I_{7}$ transition (e.g. Qin et al., 2011; Pandey and Swart, 2016). The third and most prominent emission cluster in the near-infrared wavelength range resembles observations by Yu et al. (2012), who detect a transition from ${ }^{5} F_{5}$ to ${ }^{5} I_{7}$ with emission lines at $965 \mathrm{~nm}$. A combination with processes assigned to a ${ }^{5} F_{4} /{ }^{5} S_{2}$ to ${ }^{5} I_{6}$ transition with typical emission features at longer wavelengths conjecturally explain the observed broad, intense emission cluster at $982 \mathrm{~nm}$. An influence from $\mathrm{Yb}^{3+}$ as intensifier of this spectral response (Yu et al., 2012) can be excluded by NAA results below detection limit (Donovan et al., 2002).

Depending on the embedding material of measured $\mathrm{NdPO}_{4}$ grains, the laser excitation with $325 \mathrm{~nm}$ may cause a broad-band luminescence below $700 \mathrm{~nm}$, while the use of the $442 \mathrm{~nm}$ laser revealed inefficient $\mathrm{Nd}^{3+}$ excitation. Instead, the $532 \mathrm{~nm}$ excitation proved efficient and revealed two major emission line clusters: one between 860 and $910 \mathrm{~nm}$ (maximum at $908 \mathrm{~nm}$ ) and the other one from 1040 to $1075 \mathrm{~nm}$ (maximum at $1059 \mathrm{~nm}$ ) (see Fig. 7). The two emission clusters agree with the $\mathrm{Nd}^{3+}$-related lines resulting from a ${ }^{4} F_{3 / 2}$ to ${ }^{4} I_{9 / 2}$ and a ${ }^{4} F_{3 / 2}$ to ${ }^{4} I_{11 / 2}$ transition, respectively, and resemble common observations in phosphate minerals at $532 \mathrm{~nm}$ laser excitation (Table 4) (e.g. Reisfeld et al., 1996; Gaft et al., 2005; Czaja et al., 2012; Shalapska et al., 2014). Reported emission lines below $800 \mathrm{~nm}$ by Gaft et al. (2005) are not present in any of our reference $\mathrm{NdPO}_{4}$ spectra. Shalapska et al. (2014) identified additional emissions to be too weak, of which, however, the one to ${ }^{4} I_{15 / 2}$ at $846 \mathrm{~nm}$ (cf. Gaft et al., 2005) may also be present in our reference spectrum contributing to the broad cluster around $908 \mathrm{~nm}$.

The $532 \mathrm{~nm}$ laser excitation of $\mathrm{YbPO}_{4}$ revealed a relatively weak $\mathrm{Yb}^{3+}$ emission without the strong broad-band emission at wavelengths shorter than $700 \mathrm{~nm}$ observed in several of our REE $\mathrm{PO}_{4}$ samples at $325 \mathrm{~nm}$ excitation (see Sect. 3.2). The diagnostic $\mathrm{Yb}^{3+}$ emission appears as a relatively broad band with a maximum at $1011 \mathrm{~nm}$ and a tentative shoulder 
Table 4. Overview of detected emission lines and corresponding transitions for those REEs that were successfully excited with the $532 \mathrm{~nm}$ laser.

\begin{tabular}{|c|c|c|c|}
\hline \multicolumn{4}{|c|}{$\lambda_{\text {exc }}: 532 \mathrm{~nm}$} \\
\hline Centre & $\begin{array}{r}\lambda_{\text {emi }}(\text { main }) \\
(\mathrm{nm})\end{array}$ & $\begin{array}{r}\lambda_{\text {emi }}(\text { minor }) \\
(\mathrm{nm})\end{array}$ & Transition \\
\hline \multirow[t]{3}{*}{$\mathrm{Ho}^{3+}$} & 662 & & ${ }^{5} F_{5}-{ }^{5} I_{8}$ \\
\hline & 754 & $743,747,759$ & ${ }^{5} F_{4} /{ }^{5} \mathrm{~S}_{2}-{ }^{5} I_{7}$ \\
\hline & 982 & $964,968,974,976$ & ${ }^{5} \mathrm{~F}_{5}{ }^{5} \mathrm{I}_{7}$ \\
\hline \multirow[t]{2}{*}{$\mathrm{Nd}^{3+}$} & 908 & 899 & ${ }^{4} F_{3 / 2}-{ }^{4} I_{9 / 2}$ \\
\hline & 1059 & $1046,1067,1072$ & ${ }^{4} F_{3 / 2}-{ }^{4} I_{11 / 2}$ \\
\hline $\mathrm{Yb}^{3+}$ & 1011 & 1023 & $\left({ }^{2} F_{5 / 2},{ }^{4} F_{5 / 2}\right)-{ }^{2} F_{7 / 2}$ \\
\hline
\end{tabular}

at $1023 \mathrm{~nm}$ (Fig. 7). Results correspond to the main emission line reported by Gaft et al. (2005) and Czaja et al. (2012) and reflect a $\left({ }^{2} F_{5 / 2},{ }^{4} F_{5 / 2}\right)$ to ${ }^{2} F_{7 / 2}$ recombination process (Table 4). Potentially overlapping emissions from splitting into Stark levels (Gaft et al., 1998, 2005; Czaja et al., 2012) may explain the broadened emission band with peak shoulders. The interpretation of overlapping emission lines agrees also with observations by Liang et al. (2016) who detected intense photoluminescence with main peaks at 980 and $1019 \mathrm{~nm}$ and several weak peaks at $1020-1100 \mathrm{~nm}$.

\section{Discussion}

\subsection{Suitable REE excitation wavelength}

The REE phosphate reference spectra presented above show that adequate excitation conditions can be achieved when selecting one out of the three laser wavelengths used in this study. Limiting suitable conditions for all REE to three excitation wavelengths delivers great advantages when looking for technical implications for, for example, automated, costefficient sensor solutions. The results indicate sufficient conditions for recording the main diagnostic emission lines and hence for identifying the respective REEs (with the exception of $\mathrm{GdPO}_{4}$ and $\mathrm{TmPO}_{4}$ ), although the used wavelengths do not perfectly match with the most efficient excitation wavelength of individual REEs.

The efficiency of excitation can be evaluated based on absorption spectroscopy, in which prominent absorption features indicate energy uptake by the crystal. Figure 8 depicts the three laser wavelengths $(325,442,532 \mathrm{~nm}) \mathrm{com}-$ pared to our own absorption spectra using the same REE phosphate samples from the Smithsonian library measured with the portable field spectrometer Spectral Evolution PSR 3500 (Fig. 8, orange line). Complementary, Fig. 8 shows reflectance spectra from synthetic REE phosphates presented by Ropp (1969) (black line) and reference data from REE oxides available from Kokaly et al. (2017) (grey line). We included the REE oxides as an additional reference mainly because of the wide use of this spectral library and the overall good match of absorption positions.

The laser wavelength of $325 \mathrm{~nm}$ does match with positions of absorption features for $\mathrm{Tb}^{3+}$ and $\mathrm{Dy}^{3+}$ or coincide with shoulders of absorption features for $\mathrm{Ce}^{3+}, \mathrm{Eu}^{3+}$ and potentially also for $\mathrm{Nd}^{3+}$. This superposition indicates good excitation conditions. For the other REEs, the $325 \mathrm{~nm}$ laser line lies outside or between absorption features, suggesting less suitable conditions. Blue laser excitation at $442 \mathrm{~nm}$ is most efficient for $\mathrm{Pr}^{3+}$, matches also for $\mathrm{Sm}^{3+}$ and $\mathrm{Er}^{3+}$, and overlaps with an absorption shoulder in $\mathrm{Dy}^{3+}$ and $\mathrm{Ho}^{3+}$. The $532 \mathrm{~nm}$ laser excitation was successful in particular for $\mathrm{Nd}^{3+}$ and also $\mathrm{Ho}^{3+}$. The good excitation conditions with green laser light for $\mathrm{Nd}^{3+}$ agree with other studies on excitation wavelength (e.g. Czaja et al., 2012; Lenz, 2015), while excitation at $325 \mathrm{~nm}$ was concluded to be inefficient. Figure 8 suggests that a $325 \mathrm{~nm}$ laser is also able to excite $\mathrm{Nd}$ according to the coincidence with the edge range of an absorption feature. Nevertheless, the real configuration of the crystal lattice apparently influences intensity ratios of sub-level emissions and shifting emission band positions (Lenz et al., 2013). For $\mathrm{Yb}^{3+}$, it seems surprising that the $532 \mathrm{~nm}$ and $325 \mathrm{~nm}$ excitations were successful because both excitation wavelengths lie at longer wavelengths than the absorption at $<250 \mathrm{~nm}$ shown in Ropp (1969) (see Fig. 8). However, for example, Liang et al. (2016) or Chakraborty et al. (2016) also found efficient absorption of excitation energy between 300 and $400 \mathrm{~nm}$ to charge transfer states that emit at wavelengths longer than $900 \mathrm{~nm}$. Another possible explanation may be the sensitisation of $\mathrm{Yb}^{3+}$ by traces of other REEs detected in the studied material by NAA (Donovan et al., 2002). The trace contaminations result from the reference material's production procedure, in which the chemical similarity of REEs limits the complete separation of REEs in the samples. Gaft et al. (2005) report $\mathrm{Yb}^{3+}$ excitation to be strongly dependent on Nd, but NAA results from Donovan et al. (2002) do not indicate any Nd contamination. Other potential candidates for energy transfer processes to $\mathrm{Yb}^{3+}$ are $\mathrm{Ho}$ (e.g. Wei et al., 2011; Gavrilović et al., 2015; Kang et al., 2019) (NAA mass fraction: $0.2 \pm 0.4 \times 10^{-3}$ ), Er (e.g. He et al., 2017; Wang et al., 2018; Kang et al., 2019) (NAA mass fraction: $0.2 \pm 0.2 \times 10^{-3}$ ), Tb (e.g. Gandhi et al., 2014) (NAA mass fraction: $0.2 \pm 0.3 \times 10^{-3}$ ) and Ce (e.g. Tang et al., 2018) (NAA mass fraction: $0.1 \pm 0.2 \times 10^{-3}$ ) when taking the detected trace contents of other REEs into account (NAA results given in brackets from Donovan et al., 2002).

Although ultra-violet laser wavelengths (such as $325 \mathrm{~nm}$ used in our study) seem to be preferred in analyses of REE emission spectra, the advantages of a selected use of excitation wavelengths were already recognised in many other studies, especially for $\mathrm{Pr}$ and $\mathrm{Sm}$ (blue, e.g. $442 \mathrm{~nm}$ ) and for $\mathrm{Nd}$ and Ho (green, e.g. $532 \mathrm{~nm}$ ) (e.g. Reisfeld et al., 1996; Gaft et al., 2005; Friis et al., 2010; Lorenz et al., 2019). Our results agree with those investigations and further highlight the specific drawbacks of non-suitable excitation conditions. 


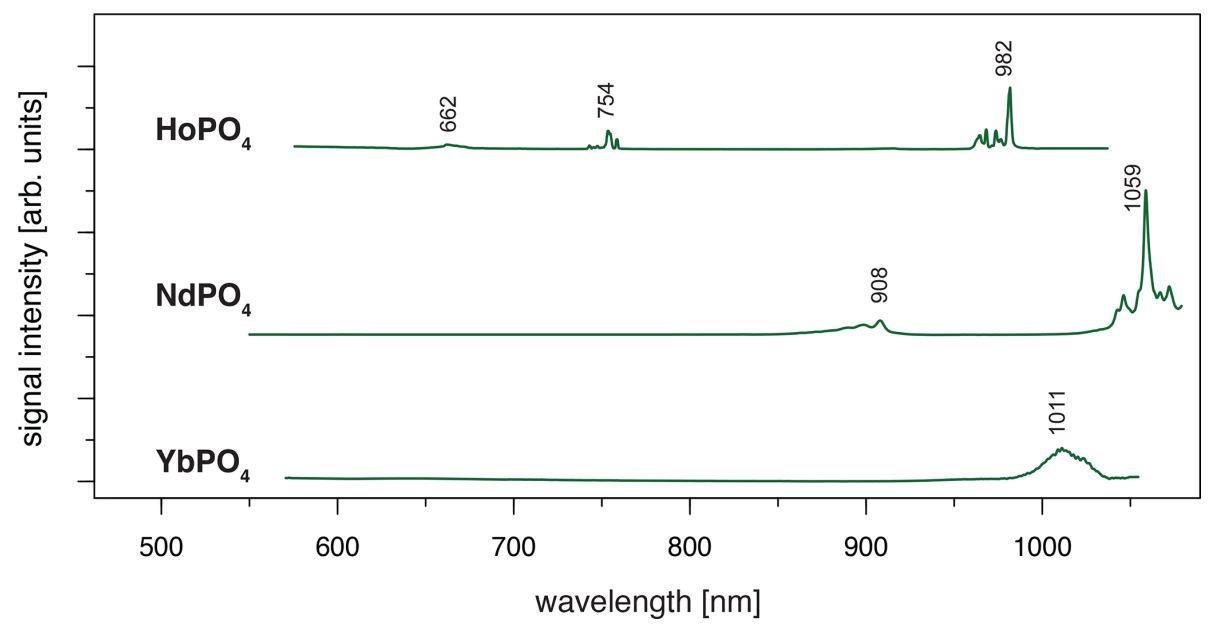

Figure 7. LiF reference spectra obtained with $532 \mathrm{~nm}$ laser excitation depict the diagnostic emission lines for the REE phosphates $\mathrm{HoPO}_{4}$, $\mathrm{NdPO}_{4}$ and $\mathrm{YbPO}_{4}$ (given values represent wavelength of most intense emission in nanometres for each transition; cf. Table 4).

For example, we observed in several of our REE $\mathrm{PO}_{4}$ samples that non-selective or high-energy excitation (in our case especially the $325 \mathrm{~nm}$ laser) seem to cause a broad-band luminescence with predominant absorption features that mask potential diagnostic REE emissions at wavelengths $<800 \mathrm{~nm}$ (see Sect. 3.2). This outlines the importance of appropriate laser wavelength selection, which in turn influences the spectral detection range. Fig. 9 shows how 442 and $532 \mathrm{~nm}$ lasers can unravel REE emission lines (see $\mathrm{HoPO}_{4}$ ) but also illustrates how improved REE signal to noise ratios may come at the cost of reduced detection ranges, which may cut off those emission lines (see $\mathrm{ErPO}_{4}$ in Fig. 9) at wavelengths shorter than the laser and long-pass filter wavelength. For example, in the case of $\mathrm{Er}^{3+}$, efficient laser excitation lines are commonly reported to be in the UV or green spectral range (e.g. Gaft et al., 2005). Our results, however, show a broad-band emission when using a UV laser that obscures the emission band around $550 \mathrm{~nm}$. The use of the $442 \mathrm{~nm}$ laser excitation enables us to record this emission, which would remain at wavelengths shorter than the detection range when using a $532 \mathrm{~nm}$ laser, although the latter shows suitable excitation conditions as well. A comparison of the absorption characteristics depicted in Fig. 8 outlines that the $532 \mathrm{~nm}$ laser is close to a very efficient excitation band and hence may be preferred in many application cases, but also the $442 \mathrm{~nm}$ laser can provide suitable excitation conditions.

To give an overview, we summarise our results with benefits and drawbacks for REE identification dependent on the selected laser wavelength used in this study in Fig. 10. Our results emphasise the potential of selective REE excitation for technical implementation or REE differentiation and the need for careful interpretation of selectively excited LiF spectra. Such a selective approach may deliver the needed tools in analyses of material with unknown, mixed REE contents such as in applications for natural rock.

\subsection{Application to natural rock samples}

Applications of the LiF spectral library for automated REE identifications have to deal with effects from overlaps, masking or energy transfer when several REEs are present in the studied material. The presence of multiple REEs may influence relative emission intensities, and also the highly variable crystal field in natural samples may influence exact emission line positions. Mixed spectra have to be expected especially from LiF of natural rocks because of the REE's similar geochemical properties and corresponding collective occurrence. Several REEs seem to compete particularly due to a concentration of emission bands in the spectral range between 500 and $700 \mathrm{~nm}$. As a result, the lines of certain REEs are more likely hidden by the stronger luminescence of other REEs. Therefore, an automated REE identification benefits from several emission bands available for peak matching and needs to account for suitable excitation conditions and effects from co-occurrence.

$\mathrm{Sm}^{3+}$, for example, shows prominent peaks at $600 \mathrm{~nm}$ (major) and $650 \mathrm{~nm}$ to be most relevant for identification, while the peak around $560 \mathrm{~nm}$ overlaps with the more prominent $\mathrm{Tb}^{3+}$ emission around $545 \mathrm{~nm}$ (Guan et al., 2016). Similarly, the same emission lines (600 and $650 \mathrm{~nm}$ ) persist when $\mathrm{Dy}^{3+}$ contributes to the measured spectrum and masks the lower $560 \mathrm{~nm}$ emission line (Gaft et al., 2005). $\mathrm{Pr}^{3+}$ is difficult to detect because its emissions are hidden by the lines of $\mathrm{Sm}^{3+}(600-650 \mathrm{~nm}), \mathrm{Dy}^{3+}(470-490 \mathrm{~nm})$ and $\mathrm{Nd}^{3+}(870$ $900 \mathrm{~nm}$ ) (Gaft et al., 2005). Blue lasers being suitable for both $\mathrm{Pr}$ and $\mathrm{Sm}$ complicate their differentiation, while for $\mathrm{Dy}^{3+}$ and $\mathrm{Nd}^{3+}$ selective excitation with UV (e.g. $325 \mathrm{~nm}$ ) or green (e.g. $532 \mathrm{~nm})$, respectively, provides an option. $\mathrm{Tm}^{3+}$ was not recorded with our system but is reported to be typically masked by $\mathrm{Tb}^{3+}$ (Gaft et al., 2005). None of the employed laser wavelengths were successful in revealing any diagnostic emission lines of $\mathrm{Tm}^{3+}$, while for both the em- 


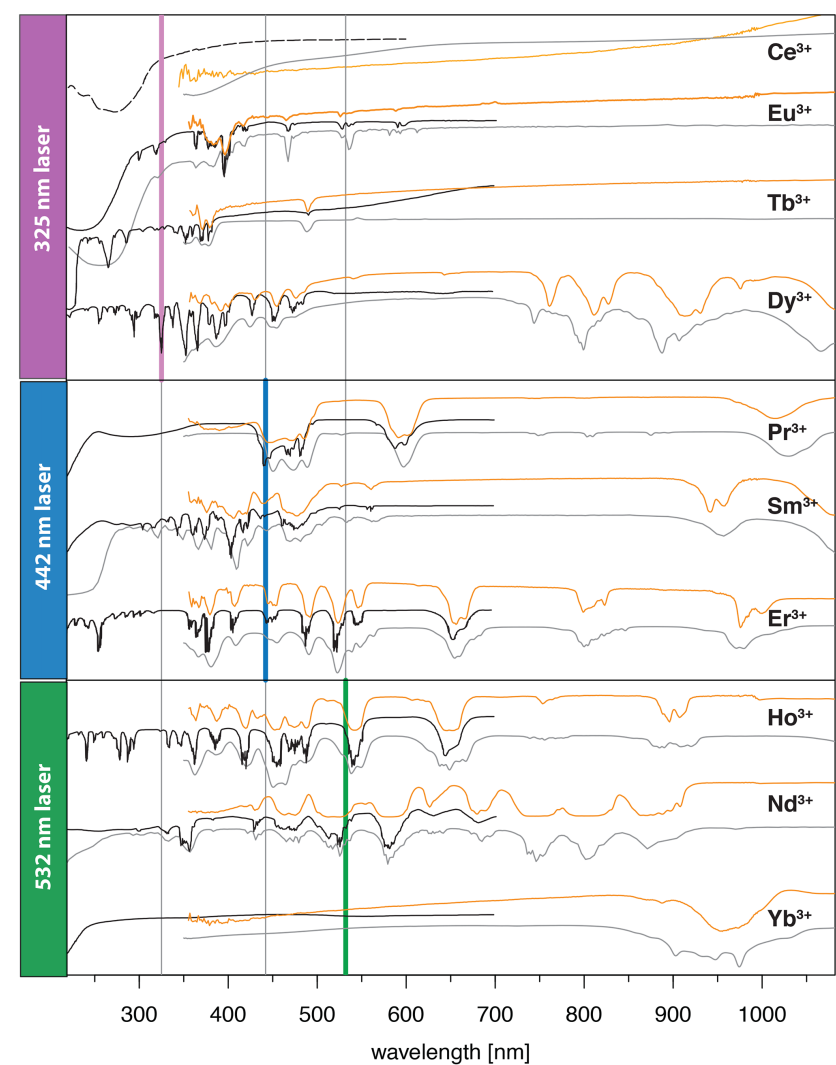

REE $\mathrm{PO}_{4}$ (own data, Smithsonian reference sample, Spectral Evolution PSR 3500) REE $\mathrm{PO}_{4}$ (published in Ropp, 1969)

$\mathrm{CePO}_{4}$ (published in Chen et al. 2014)

$\mathrm{REE}_{2} \mathrm{O}_{3}$ (USGS spectral library, only $\mathrm{Tb}^{3+}$ given as $\mathrm{TbCl}_{3}$, Kokaly et al. 2017)

Figure 8. Graphical representation of employed excitation laser wavelengths compared to reflectance spectra from our own measurements of the same REE $\mathrm{PO}_{4}$ reference samples using a Spectral Evolution PSR 3500 and two published data sets of reflectance spectra (for reference details see figure legend, $y$ axis given in arbitrary units for illustration purposes).

bedded and the single grain specimen the significant broadband luminescence in the spectral range $<700 \mathrm{~nm}$ dominated the spectra irrespective of 325,442 or $532 \mathrm{~nm}$ excitations. Therefore, our library cannot provide a Tm spectrum for further applications to identify $\mathrm{Tm}$ in mixed spectra of natural samples. Nevertheless, we detected in all resulting spectra consistent absorption features at $355-365 \mathrm{~nm}$, a doublet at 465-495 nm (most significant) and another smaller doublet at $660-710 \mathrm{~nm}$ (see Fig. 5, bottom) that agree with diagnostic absorption features of reference samples from the USGS library (Kokaly et al., 2017). Other difficulties can arise from energy transfer effects between REEs when several REEs are present, as needs to be expected in natural materials such as rocks or from cross-relaxation phenomena for high rare earth concentrations. Extensive research has been done, of which one simplified example is suppressed $\mathrm{Ho}^{3+}$ emissions in the presence of $\mathrm{Dy}^{3+}$ which can result in sensitisation of the $\mathrm{Dy}^{3+}$ characteristic emissions at 480 and $580 \mathrm{~nm}$ (Friis et al., 2010; Lenz, 2015).

An application example is given in Fig. 11 for a xenotime sample from Novo Horizonte, Brazil. The LiF reference spectra (black lines) allow for precise REE assignment to major emission peaks in the detected mixed spectra that were obtained by $325 \mathrm{~nm}$ (violet line), $442 \mathrm{~nm}$ (blue line) and $532 \mathrm{~nm}$ (green line) laser excitation. Especially Dy ${ }^{3+}$, $\mathrm{Sm}^{3+}$ and $\mathrm{Nd}^{3+}$ can be matched to the most prominent emission bands. The identified REE $\mathrm{Dy}^{3+}, \mathrm{Sm}^{3+}$ and $\mathrm{Nd}^{3+}$ (see Fig. 11) were validated by microprobe analysis (EMPA) with $7.73 \mathrm{wt} \%, 0.70 \mathrm{wt} \%$ and $0.08 \mathrm{wt} \%$, respectively (Turner, 2015; Lorenz et al., 2019). The visibility of those prominent emissions exemplifies their dependence on suitable excitation conditions (laser wavelength) and accordingly the possibility to selectively enhance or suppress the luminescence of individual REEs.

However, it is the pattern of emission bands that provides further evidence for assigning the remaining peaks to specific REEs. For example, $\mathrm{Er}^{3+}$ (EMPA: $5.26 \mathrm{wt} \%$ ) has an unequivocal peak above $850 \mathrm{~nm}$ when excited with a $442 \mathrm{~nm}$ laser, which may then be used as an indication of its contribution and better identification in remaining emission clusters. The $\mathrm{Er}^{3+}$ luminescence apparently contributes also to the emission cluster around $1000 \mathrm{~nm}$, overlapping with a potential $\mathrm{Yb}^{3+}$ emission band (EMPA: $2.51 \mathrm{wt} \%$ ), as well as to several dense emission lines around $550 \mathrm{~nm}$ which overlap with the $\mathrm{Tb}^{3+}$ emission (EMPA: $1.02 \mathrm{wt} \%$ ) recorded during $325 \mathrm{~nm}$ laser excitation.

The $442 \mathrm{~nm}$ excitation pattern further demonstrates the above-mentioned competition between REE emissions (e.g. enhancement or suppression) exemplified by bright $\mathrm{Sm}^{3+}$ emissions compared to weaker $\mathrm{Eu}^{3+}$ emissions (EMPA: $0.12 \mathrm{wt} \%)$ at partly overlapping positions. Here, the coexistence of both REEs $\left(\mathrm{Sm}^{3+}\right.$ and $\left.\mathrm{Eu}^{3+}\right)$ seems to affect the observed emission line pattern and relative intensities shown by, for example, an intense emission peak doublet at around $600 \mathrm{~nm}$ (see Fig. 11). The intensified diagnostic $\mathrm{Sm}^{3+}$ versus relatively weak $\mathrm{Eu}^{3+}$ emission lines suggest an energy transfer. The energetic transfer to $\mathrm{Sm}^{3+}$ reduces particularly the $\mathrm{Eu}^{3+}$-diagnostic emission lines at $613-622 \mathrm{~nm}$ to very low signal intensities. In the $325 \mathrm{~nm}$ excited spectrum, those $\mathrm{Eu}^{3+}$ emission lines at 613-622 nm may be present as weak signals, as well as those around $700 \mathrm{~nm}$, but the prominent $\mathrm{Dy}^{3+}$ lines preclude an unequivocal identification. Another $\mathrm{Eu}^{3+}$ sub-level at $685 \mathrm{~nm}$ is, similarly, not apparent in the $442 \mathrm{~nm}$ excited spectrum next to the intense $\mathrm{Sm}^{3+}$ emission cluster around $700 \mathrm{~nm}$. The weak to missing $\mathrm{Eu}^{3+}$ emission lines in our application example despite suitable excitation conditions with all three employed laser wavelengths in the reference material (see "Results" section and summary in Fig. 10) exemplify the difficulties of correct REE identification in natural samples with complex interactions between co-existing REEs. The three spectra excited at 325, 442 and $532 \mathrm{~nm}$ depict effects from energy transfer between 

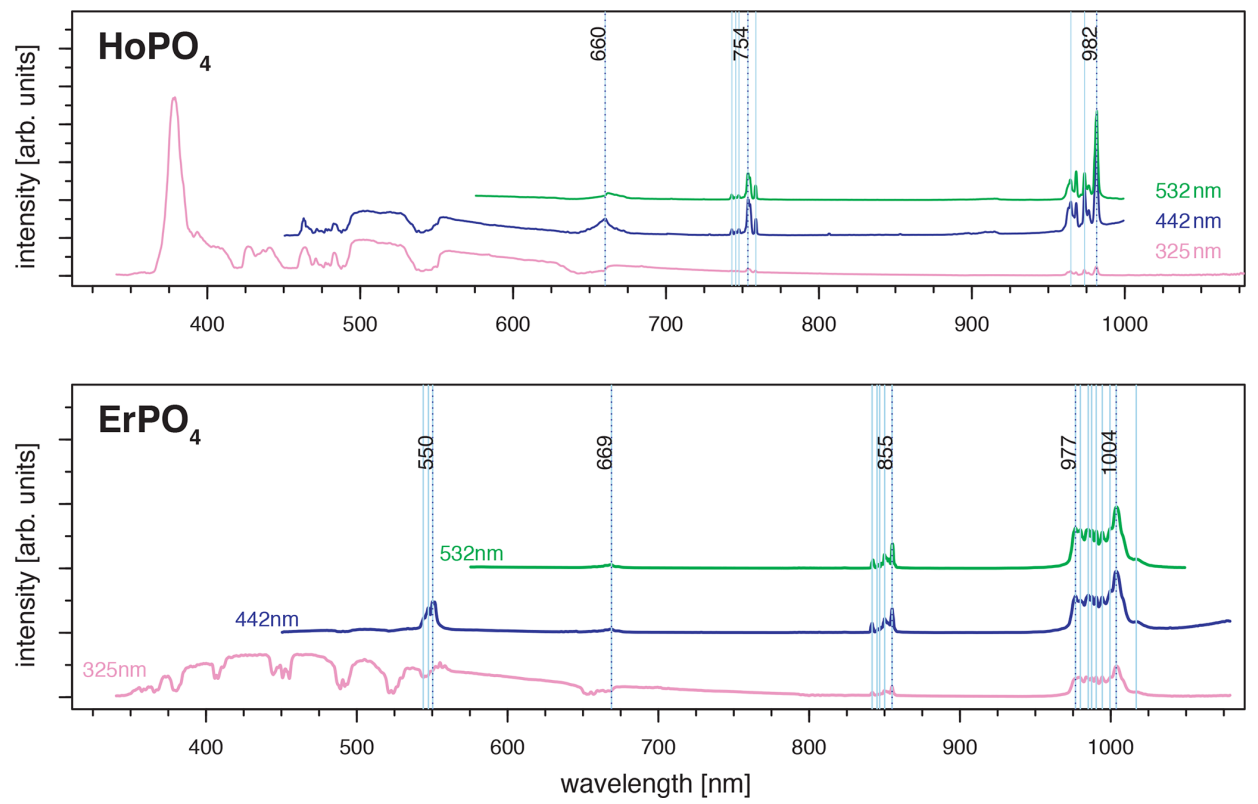

Figure 9. Evaluation of suitable laser wavelength for efficient REE excitation without unspecific broad-band luminescence (examples $\mathrm{HoPO}_{4}$ and $\mathrm{ErPO}_{4}$ ) (dotted black lines: major emissions within emission cluster; light blue lines: emission sub-levels).

REEs in line with low relative emission intensities compared to dominant emission features particularly of $\mathrm{Dy}^{3+}, \mathrm{Sm}^{3+}$, $\mathrm{Er}^{3+}$ and $\mathrm{Nd}^{3+}$ and also of $\mathrm{Yb}^{3+}, \mathrm{Ho}^{3+}, \mathrm{Tb}^{3+}$. How much the lower concentration of $\mathrm{Eu}^{3+}$ compared to the aforementioned REEs contributes to the low signal intensity is not within the scope of this study.

A change in relative emission intensities is further evident in the $532 \mathrm{~nm}$ excited xenotime spectrum at $872 \mathrm{~nm}$ (see orange question mark in Fig. 10). One potential candidate responsible for this significant peak could be $\mathrm{Nd}^{3+}$ that has a broad emission cluster in the same range but with opposite intensity ratios. Another candidate could be the rarely described near-infrared emission of $\mathrm{Sm}^{3+}$ at $872 \mathrm{~nm}$ (cf. Wang et al., 2017) that then may be ascribed to a sensitisation of this emission line as a consequence of complex energy transfers between the co-existing REEs. The excitation at $532 \mathrm{~nm}$ suggests also efficient $\mathrm{Ho}^{3+}$ stimulation (EMPA: $1.67 \mathrm{wt} \%$ ), which is a potential candidate for explaining the $750 \mathrm{~nm}$ emission overlapping with a $\mathrm{Dy}^{3+}$ position, as well as for the $1000 \mathrm{~nm}$ cluster, where it is possibly mixed with $\mathrm{Yb}^{3+}$ and $\mathrm{Er}^{3+}$. The spectroscopic analysis of the presented phosphate rock sample from Novo Horizonte shows that the new LiF spectral library for REE phosphates enables us to identify all EMPA-detected REEs, despite Tm, down to a concentration of $0.08 \mathrm{wt} \%$.

The observations confirm the valuable nature of reference spectra for natural sample evaluation and REE assignment. But the application example highlights at the same time that care needs to be taken with respect to complex effects between REEs and crystal lattice and between the REEs typically jointly occurring in natural minerals. Resulting mecha- nisms of energy transfer might influence relative peak intensities, and complex effects from the crystal field may cause shifts in exact peak positions. Differences in relative peak intensities between assigned REEs also underline the limits for quantitative conclusions. Compared to independent EMPA analysis, the $\mathrm{Er}^{3+}$-related emissions remain weak relative to, for example, $\mathrm{Sm}^{3+}$ and $\mathrm{Nd}^{3+}$ during blue and green laser excitations despite its higher concentration of $5.26 \mathrm{wt} \%$ versus $0.70 \mathrm{wt} \%$ and $0.08 \mathrm{wt} \%$, respectively. Dedicated studies are required to draw conclusions on if and how a relative quantification may be possible under which circumstances, e.g. in the same host rocks from the same parent formation system.

Additionally, we want to emphasise the fact that anion sites in minerals, typically substituted by REEs, also can be occupied by other luminescent anions (e.g. Gaft et al., 2005). For example, $\mathrm{Mn}^{2+}$ substitutes for $\mathrm{Ca}^{2+}$ or $\mathrm{Mg}^{2+}$, $\mathrm{Cr}^{3+}$ for $\mathrm{Al}^{3+}$, and others. Complexes with oxygen such as $\mathrm{WO}_{4}, \mathrm{MoO}_{4}, \mathrm{CrO}_{4}$ and $\mathrm{TiO}_{6}$ may also contribute to the observed spectra and then may obscure the REE emission lines at overlapping wavelength positions. In those cases, complementary reference spectra for the corresponding anions and complexes would help a correct identification, while more detailed luminescence measurements such as time-resolved detection are needed to unravel REE emissions behind the often broader peaks such as from $\mathrm{Mn}^{2+}$.

\section{Data availability}

The data comprising the LiF spectral library for REE orthophosphates are available via the online repository https://zenodo.org (last access: 20 July 2021), where the 


\begin{tabular}{|c|c|c|c|}
\hline & \multicolumn{3}{|c|}{ Laser wavelength } \\
\hline & $325 \mathrm{~nm}$ & $442 \mathrm{~nm}$ & $532 \mathrm{~nm}$ \\
\hline $\mathrm{CePO}_{4}$ & † $\begin{array}{l}\text { Broad-band emission } \\
\text { distinct emission in } \\
\mathrm{LuPO}_{4} \text { and } \mathrm{YPO}_{4}\end{array}$ & $\begin{array}{l}\text { Emission outside observed } \\
\text { spectral range }\end{array}$ & $\begin{array}{l}\text { Emission outside observed } \\
\text { spectral range }\end{array}$ \\
\hline $\mathrm{PrPO}_{4}$ & $\begin{array}{l}\text { A Absorptions }<750 \mathrm{~nm} \\
\text { - no distinct emission }\end{array}$ & † Distinct emission lines & (-) Inefficient excitation \\
\hline $\mathrm{NdPO}_{4}$ & $\begin{array}{l}\text { Absorptions }<750 \mathrm{~nm} \\
\text { distinct emission lines }>750 \mathrm{~nm}\end{array}$ & $=\begin{array}{l}\text { Inefficient excitation } \\
\text { distinct emission } \sim 900 \mathrm{~nm}\end{array}$ & (Distinct emission lines \\
\hline $\mathrm{SmPO}_{4}$ & $\begin{array}{l}\text { Absorptions }<750 \mathrm{~nm} \\
\text { weak emission lines } \sim 600 \mathrm{~nm}\end{array}$ & † Distinct emission lines & $\begin{array}{l}\text { Distinct emission lines } \\
\text { few emission lines below } \\
\text { observed spectral range }\end{array}$ \\
\hline $\mathrm{EuPO}_{4}$ & (Distinct emission lines & $\bigoplus$ Distinct emission lines & (Distinct emission lines \\
\hline $\mathrm{GdPO}_{4}$ & $\begin{array}{l}\text { Emission below observed } \\
\text { spectral range }\end{array}$ & $\begin{array}{l}\text { Emission below observed } \\
\text { spectral range }\end{array}$ & $\begin{array}{l}\text { Emission below observed } \\
\text { spectral range }\end{array}$ \\
\hline $\mathrm{TbPO}_{4}$ & Distinct emission lines & (Distinct emission lines & $\begin{array}{l}\text { Distinct emission lines } \\
\text { few emission lines below } \\
\text { observed spectral range }\end{array}$ \\
\hline $\mathrm{DyPO}_{4}$ & Distinct emission lines & (Distinct emission lines & $\begin{array}{l}\text { Few distinct emission lines } \\
\text { several emission lines below } \\
\text { observed spectral range }\end{array}$ \\
\hline $\mathrm{HoPO}_{4}$ & $\begin{array}{l}\text { A Absorptions }<700 \mathrm{~nm} \\
\text { weak emission lines }>700 \mathrm{~nm}\end{array}$ & $\begin{array}{l}\text { A Absorptions }<600 \mathrm{~nm} \\
\text { distinct emission lines }>600 \mathrm{~nm}\end{array}$ & (Distinct emission lines \\
\hline $\mathrm{ErPO}_{4}$ & 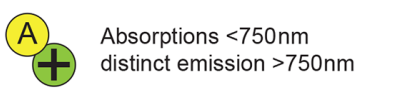 & (Distinct emission lines & †. $\begin{array}{l}\text { Distinct emission lines } \\
\text { few emission lines below } \\
\text { observed spectral range }\end{array}$ \\
\hline $\mathrm{TmPO}_{4}$ & $\begin{array}{l}\text { A. Absorptions }<750 \mathrm{~nm} \\
\text { no distinct emission }\end{array}$ & $\begin{array}{l}\text { A. Absorptions }<750 \mathrm{~nm} \\
\text { no distinct emission }\end{array}$ & $\begin{array}{l}\text { A) Absorptions }<750 \mathrm{~nm} \\
\text { no distinct emission }\end{array}$ \\
\hline $\mathrm{YbPO}_{4}$ & (Distinct emission lines & No data & (Distinct emission lines \\
\hline
\end{tabular}

- Successful REE emission line excitation

- Measurement conditions not appropriate for REE emission line excitation and/or inappropriate detection range

A Significant REE absorption features in broad-band emission

Figure 10. Summary of the evaluation of suitable laser wavelengths for an efficient excitation of individual REEs (+: good conditions; - : bad conditions; A: absorption features recorded).

data are permanently stored and registered with the DOI https://doi.org/10.5281/zenodo.4054606 (Fuchs et al., 2020). The LiF library gives open access to the spectral data under the Creative Commons Attribution 4.0 International license. You can cite all versions of the data set provided via the LiF spectral library for REE orthophosphates at https: //zenodo.org by using the given DOI to refer to Fuchs et al. (2020) and citing this article.

\section{Conclusions}

We present LiF spectra for the Smithsonian REE phosphate standards in the visible to near-infrared spectral range $(350-1080 \mathrm{~nm})$. Excitation at all three commonly used laser wavelengths $(325,442,532 \mathrm{~nm})$ yielded spectra with distinct REE-related emission lines for $\mathrm{EuPO}_{4}, \mathrm{TbPO}_{4}, \mathrm{DyPO}_{4}$ and $\mathrm{YbPO}_{4}$. At $325 \mathrm{~nm}$ excitation, most other REE spectra were dominated by broad-band defect emissions with prominent absorption features that match published reflectance data and mask expected REE emission lines. Here, lower-energy laser excitation at $442 \mathrm{~nm}$ proved successful especially for sup- 


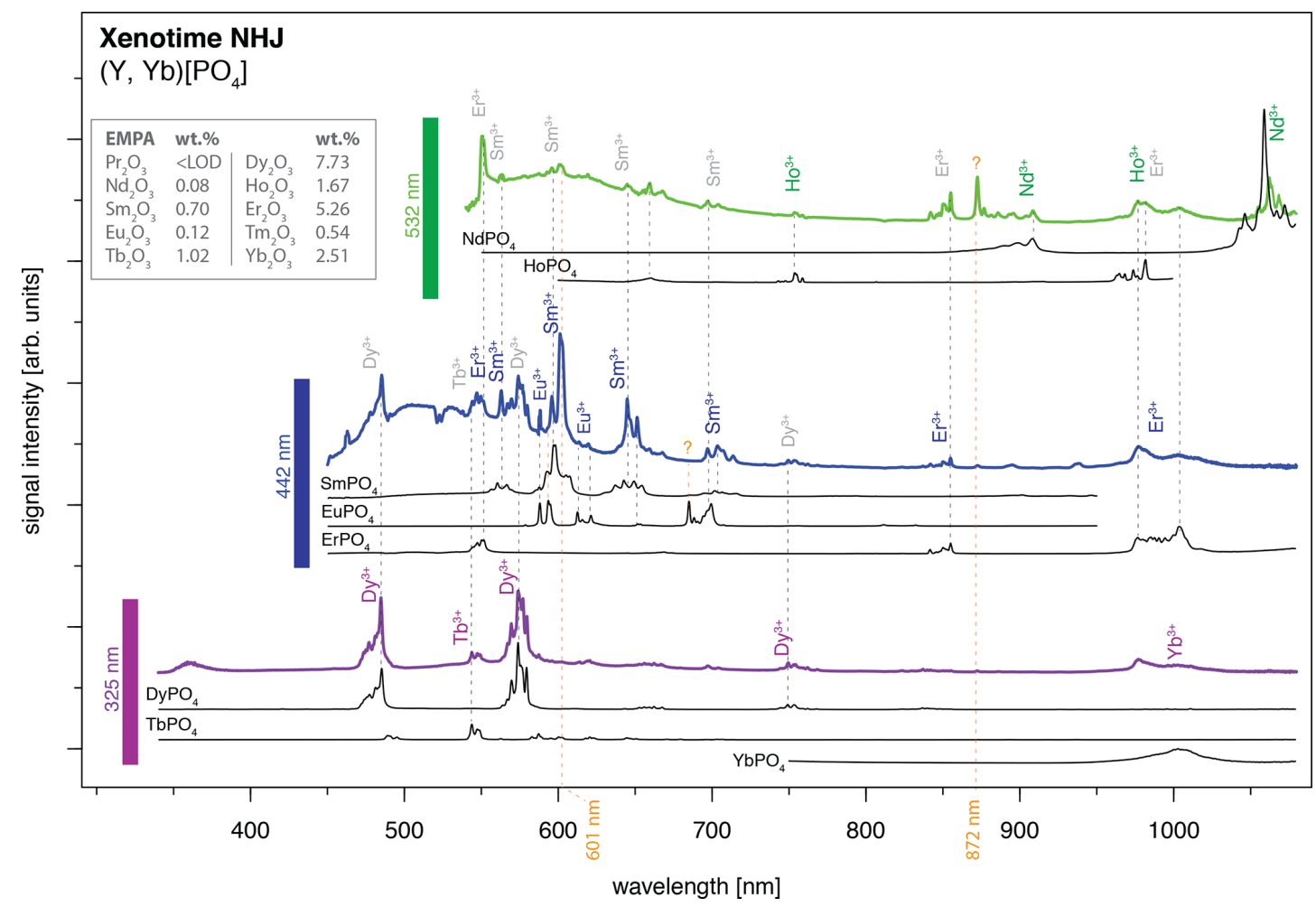

Figure 11. Application of the presented LiF spectral library for REE identification in a natural mineral: xenotime from Novo Horizonte, sample NHJ (see Turner, 2015, and Lorenz et al., 2019). The measured spectra from the three different laser excitation wavelengths are offset, and luminescence intensities of individual spectra are scaled for better visualisation of observed emission lines and potential reference emission peaks (arbitrary units: comparison of signal intensities between spectra is not meaningful).

pressing the non-REE-related broad-band luminescence. Resulting REE reference spectra include those from $\mathrm{PrPO}_{4}$, $\mathrm{SmPO}_{4}$ and $\mathrm{ErPO}_{4}$. For $\mathrm{NdPO}_{4}$ and $\mathrm{HoPO}_{4}$ the most efficient excitation was achieved with $532 \mathrm{~nm}$. The diagnostic emission lines of GdPO4 lie outside the detection range, and none of the three laser wavelengths were appropriate for $\mathrm{TmPO}_{4}$ excitation.

Our results demonstrate the suitability of LiF for REE detection and especially the possibility of selective element excitation. Our reference spectra provide the full spectral information at high resolution $(0.13 \mathrm{~nm})$ in order to allow for comprehensive analysis of emission line positions, emission line intensity ratios and splitting into emission line sub-levels. The spectral library serves as an objective database for an improved evaluation of REE-bearing natural rocks or other materials and makes a transparent comparison possible with published and future LiF measurement data. The permanent storage and open access of the data via the online repository zenodo.org and registered DOI https://doi.org/10.5281/zenodo.4054606 (Fuchs et al., 2020) provide the needed functionality for sharing and re-using the data set. Thus, the available spectral data support the use of $\mathrm{LiF}$ for REE analysis in natural samples and its application in raw material exploration, in which reference libraries are required for efficient solutions of result evaluation. Yet, the presented library is limited to trivalent REEs hosted in orthophosphates. Complementary spectral data of other economically relevant REE configurations (e.g. divalent REEs or other host minerals) are needed to further improve $\mathrm{LiF}$ capacities in REE exploration. Applications in natural rock material rely on the suppression of potentially strong matrix emissions. In this respect, selective laser wavelengths instead of high-power UV stimulation and time-resolved measurements promise considerable improvements for reliable REE identification. The three investigated laser wavelength may provide the grounds for robust technical solutions of a $\mathrm{LiF}$ sensor in exploration. Nevertheless, scientific research demands more flexible excitation conditions to optimise emission efficiency and selective detection of individual REE luminescence for in-depth analysis. Multiple complex interactions between naturally co-existing REEs and with complex variable host configurations in natural rocks still require careful interpretation of $\mathrm{LiF}$ spectra and a good understanding of luminescence principles. Detailed excitation spectra, as well as time-resolved luminescence measurements, represent valuable options for further insights into the causes and mechanisms behind the observed spectra (e.g. Czaja et al., 2013; Gaft et al., 2005). However, usage of the library for 
visual comparison or implementation into innovative automated data analysis routines facilitates identification of most probable REE candidates responsible for observed luminescence also in cases of similar emission lines but cannot replace the need for expert knowledge. The integration in particular of reflectance hyperspectral imaging provides great potential for cross-validation of REE identification and for insights into mineralisation processes.

Author contributions. MCF and JB designed and performed all experiments for data acquisition in the optical characterisation laboratory of the TU Bergakademie Freiberg. Scientific results and corresponding interpretations were extensively discussed by MCF with all co-authors regarding physical background (JB, SuS and JH) and their mineralogical and geological implications (SL, ADR and $\mathrm{RG})$. MCF prepared the manuscript with contributions from all coauthors.

Competing interests. The authors declare that they have no conflict of interest.

Disclaimer. Publisher's note: Copernicus Publications remains neutral with regard to jurisdictional claims in published maps and institutional affiliations.

Acknowledgements. We thank the Smithsonian Institution Department of Mineral Sciences and Tim Rose for providing and sending the REE phosphate samples NMNH 168484-168499 used in this study (see also https://naturalhistory.si.edu/research/ mineral-sciences/collections-overview/reference-materials/ smithsonian-microbeam-standards, last access: 20 July 2021). The scientific work was part of the EIT upscaling project inSPECtor. Data acquisition was done in the optical characterisation laboratory of the Institute of Applied Physics at the TU Bergakademie Freiberg.

Financial support. This research has been supported by the EIT RawMaterials (grant no. 16304).

Review statement. This paper was edited by Kirsten Elger and reviewed by Uwe Altenberger and one anonymous referee.

\section{References}

Ahmed, Z. and Iftikhar, K.: Red, orange-red and near-infrared light emitting ternary lanthanide tris $\beta$-diketonate complexes with distorted $\mathrm{C}_{4 v}$ geometrical structures, Dalton Trans., 48, 4973-4986, https://doi.org/10.1039/C9DT00198K, 2019.

Barakos, G., Gutzmer, J., and Mischo, H.: An outlook on the rare earth elements mining industry, AusIMM Bulletin, 2, 62-66, 2016.
Barmarin, G.: Luminescent Mineral Database, available at: http:// www.fluomin.org/uk/accueil.php, last access: 25 April 2020.

Beleites, C. and Sergo, V.: hyperSpec: a package to handle hyperspectral data sets in $\mathrm{R}, \mathrm{r}$ package version $0.99-20180627$, available at: http://hyperspec.r-forge.r-project.org (last access: 27 November 2020), 2018.

Binnemans, K.: Interpretation of europium(III) spectra, Coordin. Chem. Rev., 295, 1-45, https://doi.org/10.1016/j.ccr.2015.02.015, 2015.

Boesche, N. K., Rogass, C., Lubitz, C., Brell, M., Herrmann, S., Mielke, C., Tonn, S., Appelt, O., Altenberger, U., and Kaufmann, H.: Hyperspectral REE (Rare Earth Element) Mapping of Outcrops - Applications for Neodymium Detection, Remote Sensing, 7, 5160, https://doi.org/10.3390/rs70505160, 2015.

Booysen, R., Zimmermann, R., Lorenz, S., Gloaguen, R., Nex, P. A. M., Andreani, L., and Möckel, R.: Towards Multiscale and Multisource Remote Sensing Mineral Exploration Using RPAS: A Case Study in the Lofdal CarbonatiteHosted REE Deposit, Namibia, Remote Sensing, 11, 2500, https://doi.org/10.3390/rs11212500, 2019.

Broicher, H.: Bulk sorting by LIF: quality control of ores for bulk sorting and blending - by laser-induced fluorescence analysis, Min. Eng., 52, 24-28, 2000.

Broicher, H.: Dilution control - online and real-time recognition of ore and waste by LIF, SME Annual Meeting, 28 February2 March 2005, Salt Lake City, UT 1-5, 2005.

Chakraborty, A., Debnath, G. H., Saha, N. R., Chattopadhyay, D., Waldeck, D. H., and Mukherjee, P.: Identifying the Correct HostGuest Combination To Sensitize Trivalent Lanthanide (Guest) Luminescence: Titanium Dioxide Nanoparticles as a Model Host System, J. Phys. Chem. C, 120, 23870-23882, 2016.

Chen, H., Ni, Y., and Ma, X.: Phase-controllable synthesis, shape evolution and optical performances of $\mathrm{CePO}_{4}$ nanocrystals via a simple oil-bath route, RSC Adv., 4, 36553-36559, https://doi.org/10.1039/C4RA07052F, 2014.

CSIRO: CSIRO Luminescence database, available at: https:// luminescence.csiro.au/luminescence/default.aspx, last access: 1 August 2019.

Czaja, M., Bodyl-Gajowska, S., Gluchowski, P., Mazurak, Z., and Strek, W.: Luminescence properties of rare earth ions in fluorite, apatite and scheelite mineral, J. Alloy. Compd., 451, 290-292, https://doi.org/10.1016/j.jallcom.2007.04.058, 2008.

Czaja, M., Bodyl-Gajowska, S., Lisiecki, R., Meijerink, A., and Mazurak, Z.: The luminescence properties of rare-earth ions in natural fluorite, Phys. Chem. Miner., 39, 639-648, https://doi.org/10.1007/s00269-012-0518-8, 2012.

Czaja, M., Bodyl-Gajowska, S., and Mazurak, Z. G.: Steadystate luminescence measurement for qualitative identification of rare earth ions in minerals, J. Miner. Petrol. Sci., 108, 47-54, https://doi.org/10.2465/jmps.111229, 2013.

Donovan, J., Hanchar, J., Picolli, P., Schrier, M., Boatner, L., and Jarosewich, E.: Contamination in the rare-earth element orthophosphate reference samples, J. Res. Natl. Inst. Stan., 106, 693-701, https://doi.org/10.6028/jres.107.056, 2002.

Donovan, J., Hanchar, J., Piccoli, P., Schrier, M., Boatner, L., and Jarosewich, E.: A reexamination of the rareearth element orthophosphate reference samples for electron microprobe analysis, Can. Mineral., 41, 221-232, https://doi.org/10.2113/gscanmin.41.1.221, 2003. 
Emsbo, P., McLaughlin, P. I., Breit, G. N., du Bray, E. A., and Koenig, A. E.: Rare earth elements in sedimentary phosphate deposits: Solution to the global REE crisis?, Gondwana Res., 27, 776-785, https://doi.org/10.1016/j.gr.2014.10.008, 2015.

European Commission: Report on critical raw materials for the EU, Report of the Ad-hoc Working Group on defining critical raw materials, European Commission, availablea at: https://ec.europa.eu/docsroom/documents/10010/attachments/1/ translations/en/renditions/pdf (last access: 20 July 2021), 2014.

European Commission: Report on critical raw materials and the Circular Economy, European Commission, Brussels, available at: https://op.europa.eu/de/publication-detail/-/publication/ d1be1b43-e18f-11e8-b690-01aa75ed71a1/language-en/ format-PDF/source-80004733 (last access: 20 July 2021), 2018.

Fang, H., Wei, X., Zhou, S., Li, X., Chen, Y., Duan, C.-K., and Yin, M.: Terbium and holmium codoped yttrium phosphate as noncontact optical temperature sensors, RSC Adv., 7, 10200-10205, https://doi.org/10.1039/C6RA27971F, 2017.

Fasnacht, L., Vogt, M.-L., Renard, P., and Brunner, P.: A 2D hyperspectral library of mineral reflectance, from 900 to $2500 \mathrm{~nm}$, Sci. Data, 6, 268, https://doi.org/10.1038/s41597-019-0261-9, 2019.

Friis, H., Finch, A., Williams, C., and Hanchar, J.: Photoluminescence of zircon $\left(\mathrm{ZrSiO}_{4}\right)$ doped with $\mathrm{REE}^{3+}(\mathrm{REE}=\mathrm{Pr}$, Sm, Eu, Gd, Dy, Ho, Er), Phys. Chem. Miner., 37, 333-342, https://doi.org/10.1007/s00269-009-0336-9, 2010.

Fuchs, M. C., Beyer, J., Lorenz, S., Sharma, S., Renno, A. D., Heitmann, J., and Gloaguen, R.: Spectral library of laserinduced fluorescence $(\mathrm{LiF})$ properties from Smithsonian rareearth element (REE) orthophosphate standards, Zenodo [data set], https://doi.org/10.5281/zenodo.4054606, 2020.

Gaft, M. and Panczer, G.: Laser-induced time-resolved luminescence spectroscopy of minerals - a powerful tool for studying the nature of emission centres, Miner. Petrol., 107, 363-373, https://doi.org/10.1007/s00710-013-0293-3, 2013.

Gaft, M., Reisfeld, R., Panczer, G., Blank, P., and Boulon, G.: Laser-induced time-resolved luminescence of minerals, Spectrochim. Acta A, 54, 2163-2175, https://doi.org/10.1016/S13861425(98)00134-6, 1998.

Gaft, M., Reisfeld, R., and Panczer, G.: Modern luminescence spectroscopy of minerals and materials, 1st Edn., Springer-Verlag, Berlin Heidelberg, https://doi.org/10.1007/b137490, 2005.

Gandhi, M., Agrawal, N., and Bhatia, H.: Quantum Cutting down Conversion by Cooperative Energy Transfer from $\mathrm{Tb}^{3+}$ to $\mathrm{Yb}^{3+}$ in $\mathrm{CeF}_{3}$ Nanophosphors, in: Energy Development, vol. 860 of Advanced Materials Research, Trans Tech Publications Ltd, 124-127, https://doi.org/10.4028/www.scientific.net/AMR.860863.124, 2014.

Gavrilović, T. V., Jovanović, D. J., Trandafilović, L. V., and Dramićanin, M. D.: Effects of $\mathrm{Ho}^{3+}$ and $\mathrm{Yb}^{3+}$ doping concentrations and $\mathrm{Li}^{+}$co-doping on the luminescence of $\mathrm{GdVO}_{4}$ powders, Opt. Mater., 45, 76-81, https://doi.org/10.1016/j.optmat.2015.03.013, 2015.

Goodenough, K., Schilling, J., Jonsson, E., Kalvig, P., Charles, N., Tuduri, J., Deady, E., Sadeghi, M., Schiellerup, H., Müller, A., Bertrand, G., Arvanitidis, N., Eliopoulos, D., Shaw, R., Thrane, K., and Keulen, N.: Europe's rare earth element resource potential: An overview of REE metallogenetic provinces and their geodynamic setting, Ore Geol. Rev., 72, 838-856, https://doi.org/10.1016/j.oregeorev.2015.09.019, 2016.

Guan, H., Sheng, Y., Song, Y., Zheng, K., Xu, C., Xie, X., Dai, Y., and Zou, H.: White light-emitting, tunable color luminescence, energy transfer and paramagnetic properties of terbium and samarium doped $\mathrm{BaGdF}_{5}$ multifunctional nanomaterials, RSC Adv., 6, 73160-73169, https://doi.org/10.1039/C6RA14296F, 2016.

Ha, H. M., Hoa, T. T. Q., Vu, L. V., and Long, N. N.: Photoluminescence and Energy Transfer Between $\mathrm{Sm}^{3+}$ Ions in $\mathrm{LaF}_{3}$ Nanocrystals Prepared by Hydrothermal Method, International Journal of Materials Science and Applications, 5, 284289, https://doi.org/10.11648/j.ijmsa.20160506.18, 2016.

He, S., Xia, H., Zhang, J., Zhu, Y., and Chen, B.: Highly efficient upconversion luminescence in $\mathrm{Er}^{3+} / \mathrm{Yb}^{3+}$ co-doped $\mathrm{Na}_{5} \mathrm{Lu}_{9} F_{32}$ single crystals by vertical Bridgman method, Sci. Rep., 7, 8751, https://doi.org/10.1038/s41598-017-09222-0, 2017.

Jarosewich, E. and Boatner, L.: Rare-earth element reference samples for electron microprobe analysis, Geostandard. Newslett., 15, 397-399, https://doi.org/10.1111/j.1751908X.1991.tb00115.x, 1991.

Kalashnikov, A., Konopleva, N., Ivanyuk, G., and Pakhomovsky, Y.: Rare Earth Deposits of the Murmansk Region, Russia - A Review, Econ. Geol., 111, 1529-1559, https://doi.org/10.2113/econgeo.111.7.1529, 2016.

Kang, X., Lü, W., Wang, H., and Ling, D.: Multicolortunable up-conversion emissions of $\mathrm{Yb}^{3+}, \mathrm{Er}^{3+} / \mathrm{Ho}^{3+}$ codoped $\mathrm{Ba}_{3} \mathrm{Lu}_{2} \mathrm{Zn}_{5} \mathrm{O}_{11}$ : crystal structure, luminescence and energy transfer properties, Dalton Trans., 48, 2917-2925, https://doi.org/10.1039/C8DT04577A, 2019.

Kauppinen, T., Khajehzadeh, N., and Haavisto, O.: Laser-induced fluorescence images and Raman spectroscopy studies on rapid scanning of rock drillcore samples, Int. J. Miner. Process., 132, 26-33, https://doi.org/10.1016/j.minpro.2014.09.003, 2014.

Kokaly, R., Clark, R., Swayze, G., Livo, K., Hoefen, T., Pearson, N., Wise, R., Benzel, W., Lowers, H., Driscoll, R., and Klein, A.: USGS Spectral Library Version 7, Tech. Rep. 1035, U.S. Geological Survey Data Series, https://doi.org/10.3133/ds1035, 2017.

Lafuente, B., Downs, R. T., Yang, H., and Stone, N.: he power of databases: the RRUFF project, in: Highlights in Mineralogical Crystallography, edited by: Armbruster, T. and Danisi, R. M., W. De Gruyter, Berlin, Germany, 1-30, 2015.

Lenz, C.: Luminescence of Lanthanoides (Rare-earth elements) Probes of structural variations in minerals, $\mathrm{PhD}$ thesis, University of Vienna, 2015.

Lenz, C., Talla, D., Ruschel, K., Škoda, R., Götze, J., and Nasdala, L.: Factors affecting the $\mathrm{Nd}^{3+}\left(\mathrm{REE}^{3+}\right)$ luminescence of minerals, Miner. Petrol., 107, 415-428, https://doi.org/10.1007/s00710-013-0286-2, 2013.

Liang, Y.-J., Liu, F., Chen, Y.-F., Wang, X.-J., Sun, K.-N., and Pan, $\mathrm{Z}$.: New function of the $\mathrm{Yb}^{3+}$ ion as an efficient emitter of persistent luminescence in the short-wave infrared, Light Science Applications, 5, e16124, https://doi.org/10.1038/lsa.2016.124, 2016.

Liang, Y.-J., Liu, F., Chen, Y., Wang, X., Sun, K., and Pan, Z.: Red/near-infrared/short-wave infrared multi-band persistent luminescence in $\mathrm{Pr}^{3+}$-doped persistent phosphors, Dalton Trans., 46, 11149, https://doi.org/10.1039/c7dt02271a, 2017. 
Lima, I. B. D. and Filho, W. L. (Eds.): Rare Earths Industry - Technological, Economic, and Environmental Implications, Elsevier, Boston, https://doi.org/10.1016/C2014-0-01863-1, 2015.

Lorenz, S., Beyer, J., Fuchs, M., Seidel, P., Turner, D., Heitmann, J., and Gloaguen, R.: The Potential of Reflectance and Laser Induced Luminescence Spectroscopy for Near-Field Rare Earth Element Detection in Mineral Exploration, Remote Sensing, 11, 21, https://doi.org/10.3390/rs11010021, 2019.

National Research Council: Minerals, Critical Minerals, and the U.S. Economy, The National Academies Press, Washington, DC, https://doi.org/10.17226/12034, 2008.

Nazarov, M., Tsukerblat, B., Byeon, C., Arellano, I., Popovici, E.J., and Noh, D.: Polarization selection rules and optical transitions in terbium activated yttrium tantalate phosphor under x-ray, vacuum-ultraviolet, and ultraviolet excitations, Appl. Optics, 48, 17-21, https://doi.org/10.1364/AO.48.000017, 2009.

Neave, D. A., Black, M., Riley, T. R., Gibson, S. A., Ferrier, G., Wall, F., and Broom-Fendley, S.: On the Feasibility of Imaging Carbonatite-Hosted Rare Earth Element Deposits Using Remote Sensing, Econ. Geol., 111, 641-665, https://doi.org/10.2113/econgeo.111.3.641, 2016.

Nienhaus, K. and Bayer, A.: Innovative Systems for Horizon Control of Mining Machines by Means of Laser Induced Fluorescence (LIF), Mine Planning and Equipment Selection, Kalgoorlie, WA, 1-7, 2003.

Pandey, A. and Swart, H. C.: Luminescence investigation of visible light emitting $\mathrm{Ho}^{3+}$ doped tellurite glass, J. Lumin., 169, 93-98, https://doi.org/10.1016/j.jlumin.2015.08.060, 2016.

Prasad, V. R., Damodaraiah, S., Devara, S., and Ratnakaram, Y.: Photoluminescence studies on holmium (III) and praseodymium (III) doped calcium borophosphate (CBP) phosphors, J. Mol. Struct., 1160, 383-392, https://doi.org/10.1016/j.molstruc.2018.02.034, 2018.

Qin, F., Zheng, Y., Yu, Y., Cheng, Z., Tayebi, P. S., Cao, W., and Zhang, Z.: Ultraviolet and violet upconversion luminescence in $\mathrm{Ho}^{3+}$-doped $\mathrm{Y}_{2} \mathrm{O}_{3}$ ceramic induced by 532-nm CW laser, J. Alloy. Compd., 509, 1115-1118, https://doi.org/10.1016/j.jallcom.2010.09.188, 2011.

R Core Team: R: A Language and Environment for Statistical Computing, R Foundation for Statistical Computing, Vienna, Austria, available at: http://www.R-project.org (last access: 20 July 2021), 2014.

Reisfeld, R., Gaft, M., Boulon, G., Panczer, C., and Jørgensen, C.: Laser-induced luminescence of rare-earth elements in natural fluor-apatites, J. Lumin., 69, 343-353, https://doi.org/10.1016/S0022-2313(96)00114-7, 1996.

Ropp, R.: Phosphors Based on Rare Earth Phosphates: II. Reflection Spectra of Rare Earth Phosphates, J. Electrochem. Soc., 116, 623-629, https://doi.org/10.1149/1.2411989, 1969.

Runowski, M., Woźny, P., Martín, I. R., Lavín, V., and Lis, S.: Praseodymium doped YF3:Pr3+ nanoparticles as optical thermometer based on luminescence intensity ratio (LIR) Studies in visible and NIR range, J. Lumin., 214, 116571, https://doi.org/10.1016/j.jlumin.2019.116571, 2019.

Samanta, T., Sarkar, S., Adusumalli, V. N. K. B., Praveen, A. E., and Mahalingam, V.: Enhanced visible and near infrared emissions via $\mathrm{Ce}^{3+}$ to $\mathrm{Ln}^{3+}$ energy transfer in $\mathrm{Ln}^{3+}$-doped $\mathrm{CeF}_{3}$ nanocrystals $(\mathrm{Ln}=\mathrm{Nd}$ and $\mathrm{Sm})$, Dalton Trans., 45, 78-84, https://doi.org/10.1039/c5dt02974k, 2016.
Seidel, P., Lorenz, S., Heinig, T., Zimmermann, R., Booysen, R., Beyer, J., Heitmann, J., and Gloaguen, R.: Fast 2D Laser-Induced Fluorescence Spectroscopy Mapping of Rare Earth Elements in Rock Samples, Sensors, 19, 2219, https://doi.org/10.3390/s19102219, 2019.

Shalapska, T., Dorenbos, P., Gektin, A., Stryganyuk, G., and Voloshinovskii, A.: Luminescence spectroscopy and energy level location of lanthanide ions doped in $\mathrm{La}\left(\mathrm{PO}_{3}\right)_{3}$, J. Lumin., 155, 95-100, https://doi.org/10.1016/j.jlumin.2014.06.029, 2014.

Sharma, S. K., Köhler, T., Beyer, J., Fuchs, M., Gloaguen, R., and Heitmann, J.: Extending the temperature sensing range using Eu3+ luminescence up to $865 \mathrm{~K}$ in a single crystal of EuPO4, Phys. Chem. Chem. Phys., 21, 16329-16336, https://doi.org/10.1039/C9CP03501J, 2019.

Smithsonian National Museum of Natural History: Smithsonian microbeam standards data sheet, available at: https://naturalhistory. si.edu/research/mineral-sciences/collections-overview/ reference-materials/smithsonian-microbeam-standards, last access: 10 October 2019.

Tang, L., Ye, H., and Xiao, D.: Photo-induced luminescence degradation in $\mathrm{Ce}, \mathrm{Yb}$ co-doped yttrium aluminum garnet phosphors, Appl. Optics, 57, 7627-7633, https://doi.org/10.1364/AO.57.007627, 2018.

Turner, D. J.: Reflectance spectroscopy and imaging spectroscopy of rare earth element-bearing mineral and rock samples, $\mathrm{PhD}$ thesis, University of British Columbia, 2015.

Turner, D. J., Rivard, B., and Groat, L. A.: Visible and short-wave infrared reflectance spectroscopy of REE fluorocarbonates, Am/ Mineral/, 99, 1335-1346, https://doi.org/10.2138/am.2014.4674, 2014.

Wang, S., Xu, J., Wang, J., Wang, K.-Y., Dang, S., Song, S., Liu, D., and Wang, C.: Luminescence of samarium(iii) bisdithiocarbamate frameworks: codoped lanthanide emitters that cover visible and near-infrared domains, J. Mater. Chem. C, 5, 6620-6628, https://doi.org/10.1039/C7TC01844D, 2017.

Wang, X., Li, X., Zhong, H., Xu, S., Cheng, L., Sun, J., Zhang, J., Li, L., and Chen, B.: Up-conversion luminescence, temperature sensing properties and laser-induced heating effect of $\mathrm{Er}^{3+} / \mathrm{Yb}^{3+}$ co-doped $\mathrm{YNbO}_{4}$ phosphors under $1550 \mathrm{~nm}$ excitation, Sci. Rep., 8, 5736, https://doi.org/10.1038/s41598-01823981-4, 2018.

Wantana, N., Kaewjaeng, S., Kothan, S., Kim, H. J., and Kaewkhao, J.: Energy transfer from $\mathrm{Gd}^{3+}$ to $\mathrm{Sm}^{3+}$ and luminescence characteristics of $\mathrm{CaO}-\mathrm{Gd}_{2} \mathrm{O}_{3}-\mathrm{SiO}_{2}-$ $\mathrm{B}_{2} \mathrm{O}_{3}$ scintillating glasses, J. Lumin., 181, 382-386, https://doi.org/10.1016/j.jlumin.2016.09.050, 2017.

Wei, X., Li, Y., Cheng, X., Chen, Y., and Yin, M.: Strong dependence of upconversion luminescence on doping concentration in holmium and ytterbium co-doped $\mathrm{Y}_{2} \mathrm{O}_{3}$ phosphor, J. Rare Earths, 29, 536-539, https://doi.org/10.1016/S10020721(10)60493-0, 2011.

White, W. B.: Diffuse-reflectance spectra of rare-earth oxides, Appl. Spectrosc., 21, 167-171, 1967.

Yashodha, S. R., Dhananjaya, N., and Manjunath, C.: Synthesis and photoluminescence properties of $\mathrm{Sm}^{3+}$ doped $\mathrm{LaOCl}$ phosphor with reddish orange emission and it's Judd-Ofelt analysis, Mater. Res Express, 7, 015003, https://doi.org/10.1088/20531591/ab57a6, 2019. 
Yu, D. C., Ye, S., Huang, X. Y., and Zhang, Q. Y.: Enhanced three-photon near-infrared quantum splitting in $\beta$ NaYF4:Ho ${ }^{3+}$ by codoping $\mathrm{Yb}^{3+}$, AIP Adv., 2, 022124, https://doi.org/10.1063/1.4718412, 2012.

Zhou, B., Tao, L., Tsang, Y. H., Jin, W., and Pun, E. Y.B.: Superbroadband near-IR photoluminescence from $\mathrm{Pr}^{3+}$ doped fluorotellurite glasses, Opt. Express, 20, 3803-3813, https://doi.org/10.1364/OE.20.003803, 2012.

Zimmermann, R., Brandmeier, M., Andreani, L., Mhopjeni, K., and Gloaguen, R.: Remote Sensing Exploration of Nb-Ta-LREEEnriched Carbonatite (Epembe/Namibia), Remote Sensing, 8, 620, https://doi.org/10.3390/rs8080620, 2016.
Zirner, A. L., Marks, M. A., Wenzel, T., Jacob, D. E., and Markl, G.: Rare earth elements in apatite as a monitor of magmatic and metasomatic processes: The Ilímaussaq complex, South Greenland, Lithos, 228-229, 12-22, https://doi.org/10.1016/j.lithos.2015.04.013, 2015. 